\title{
دور أغانى الاطفال المقدمة بالقنوات التليفزيزنية المتخصصة فى تنمية المهارات الاجتماعية لاى الاطفال
}

\author{
د/ ياسر ميمون عباس \\ مدرس اصول التربية بقسم العلوم \\ التربوية والنفسية كلية التربية النوعية- \\ جامعة المنوفية

\section{مها طارق محمد زكى} \\ أخصائى علاقات ثقافية بكلية التربية النوعية
}

\author{
أ.م.د / وسام نصر

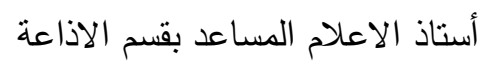 \\ والتليفزيون كلية الاعلام -جامعة القاهرة \\ د/ بسنت عبد المحسن العقباوى \\ مدرس بقسم الاعلام التزبوى كلية التربية \\ النوعية- جامعة المنوفية
}

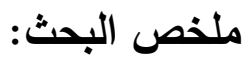

يهـدف البحـث إلى التعـرف على دور اغـانى الأطفـال المقدمـة بـالقنوات التليفزيونيـة

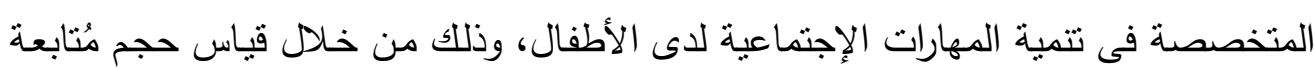

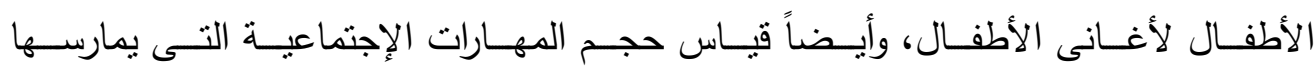

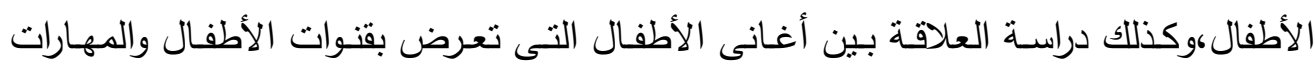
الإجتماعية التى يكتسبها الطفل ، وتتنمى هذه الدراسة إلى الدراسـات الوصفية، وفى إطارها استخدمت الباحثة منهج المسح الإعلامس، واستخدمت فى ذلك استمارة الاستبيان ومقياسـاً

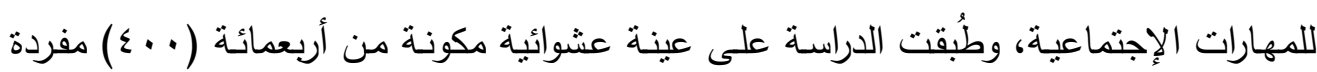

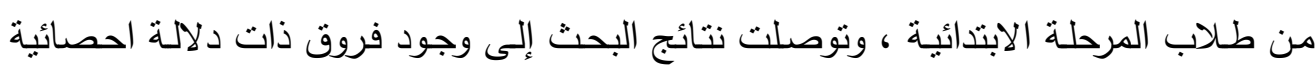

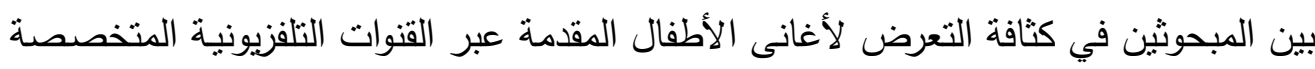

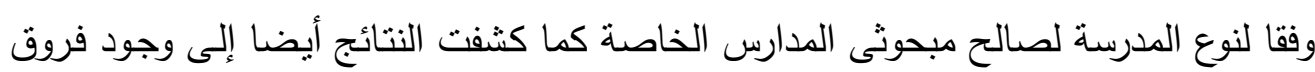
ذات دلالة إحصائية بين متوسطات درجات المبحوثين على مقياس المهارات الاجتماعية تبعا

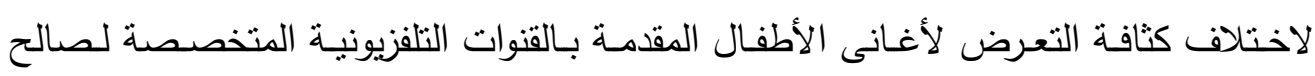

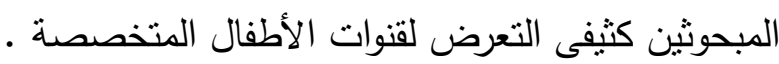




\section{"The role of the children's songs provided by the TV}

\section{channels specialized in the development of social skills in children."}

\section{Abstract:}

The study aims to identify the role of children's songs provided by television channels specialized in the development of social skills in children by measuring children's follow-up of children's songs and measuring the social skills of children .It also examines the relationship between children's songs that shows the children's channels and the social skills acquired by the child, this study belongs to the descriptive studies, in which the researcher used the media survey method, and used the questionnaire and a measure of social skills. The study was applied to a random sample of four hundred $(\xi \cdots)$ for the primary stage. The study reached a number of results, the most important of which are:There were statistically significant differences among the subjects in the intensity of exposure to children's songs provided through specialized television channels according to the type of school for the benefit of the respondents of private schools and There were statistically significant differences between the mean scores of the subjects on the scale of social skills according to different intensity of exposure to children's songs provided by specialized T.V channels for the benefit of respondents with a high exposure to specialized children's channels. 


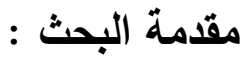

إن قدرة التليفزيون بما لديه من طاقات فنية وجهود بشرية وآلية ، وثقنيات علمية منطورة

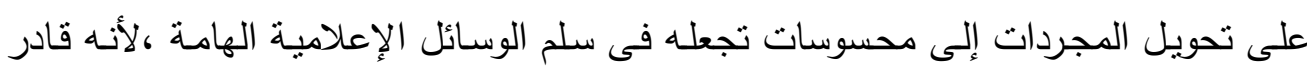

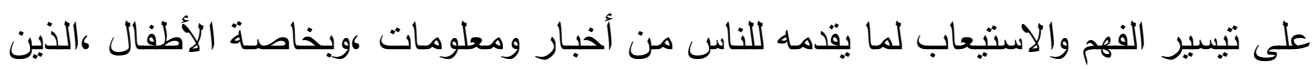

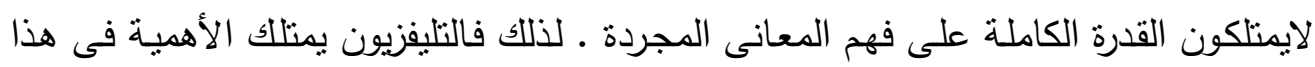

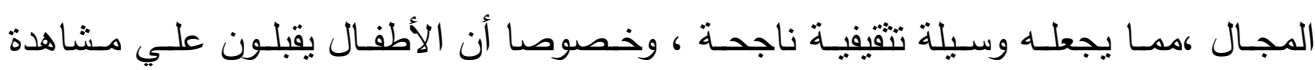

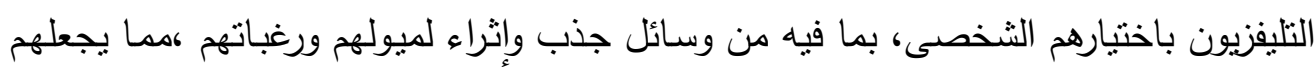
يركزون على ما يعرض عليهم . لئل

وفى ظل هذه الفترة يعتبر التليفزيون من أهم وسائل الاتصال وأخطرها فى نفس الوقت ،

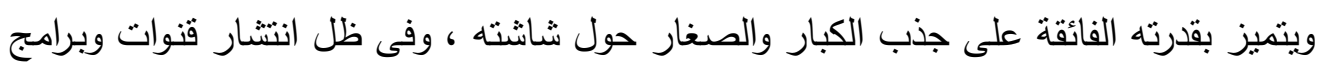

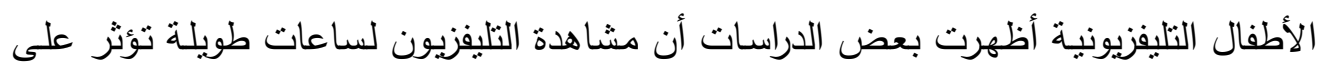

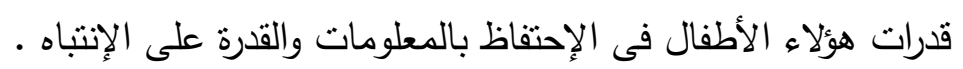

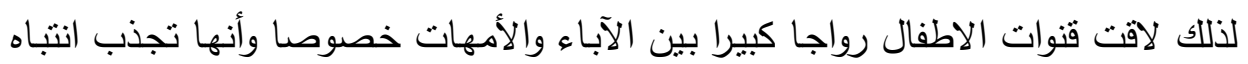

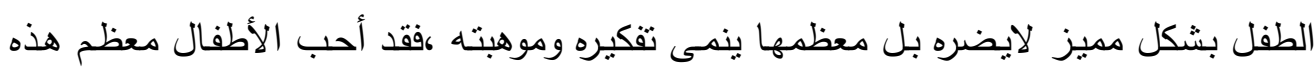
القنوات الفضائية التى جعلت كل تركيزها وشغلها الشاغل الطفل العربى وكيفية إفادته بشكل معلئل

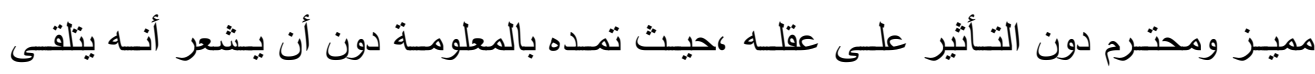
المعلومات لذلك نجد أن معظم قنوات الأطفال تقدم موادها على شكل أغانى ورسوم متحركة .

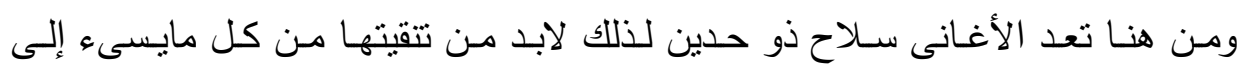

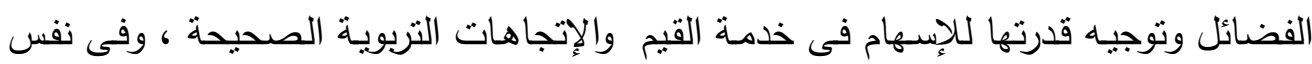

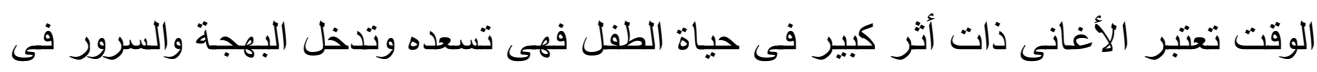

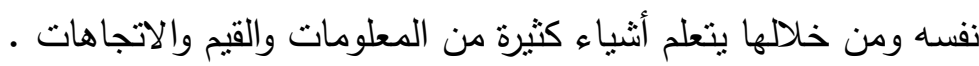

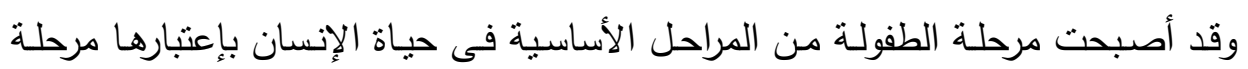

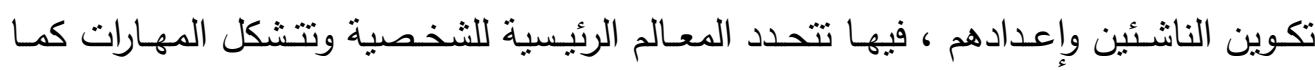

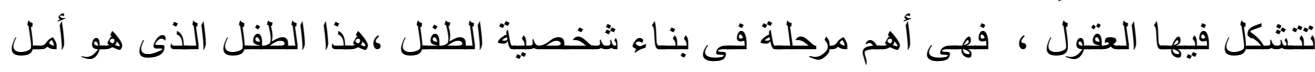

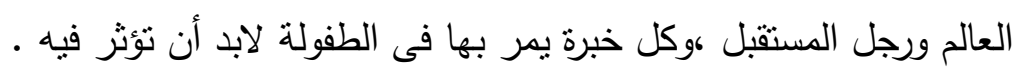

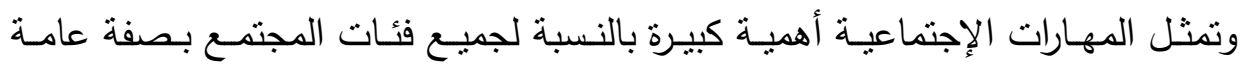

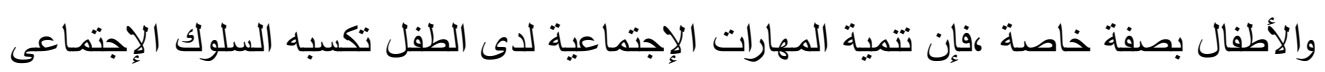

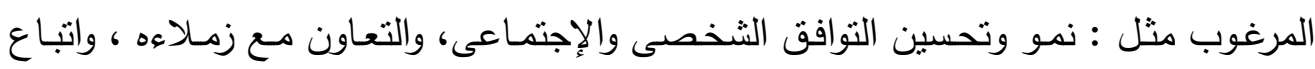

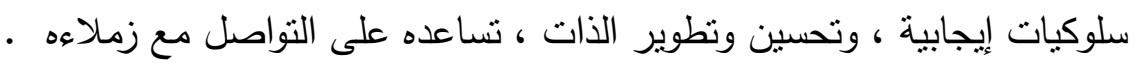


الأغانى والأناشيد ذات أهمية كبيرة للكبار والصغار ولكنها أكثر أهمية بمـا فيها من موسيقى وإيقاع ،وصور تخاطب الوجدان وتثير فى النفس الفن والجمال ، ويمكن أن تكون الأغنية عاملا

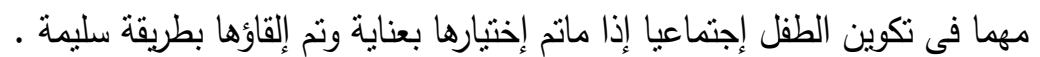

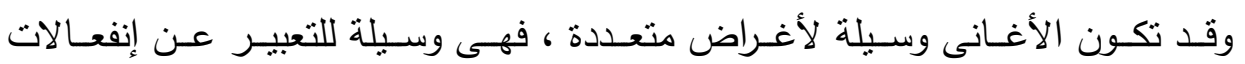

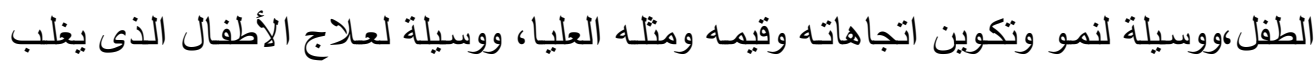

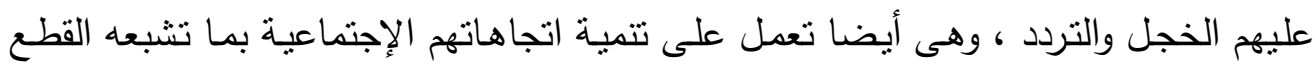

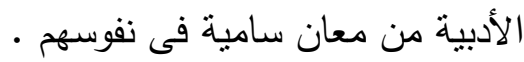

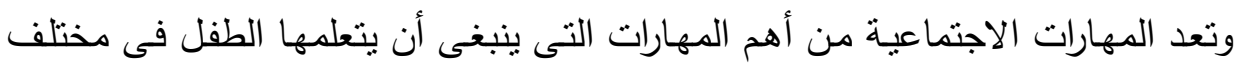

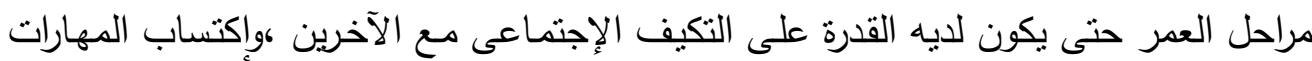

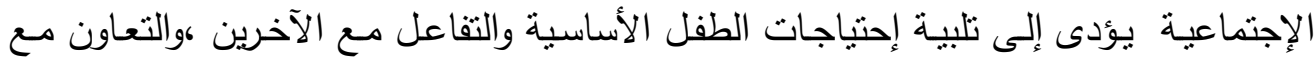

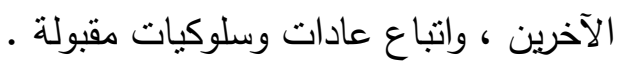
ومن ثم يمكن بلورة مشكلة الدراسة فى الإجابة على التساؤل التالى :

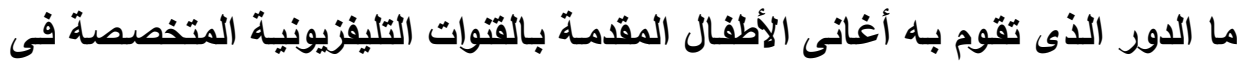
تنمية المهارات الإجتماعية لاى الأطفال ؟ وينبيثق من هذا التساؤل الرئيسى عدة تساؤلات فرعية كالآتى الاطفال :

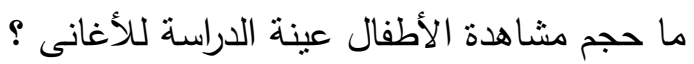
ما حجم ممارسة الأطفال عينة الدراسة للمهارات الإجتماعية ؟ ما أكثر الأغانى متابعة من قبل الأطفال ؟ مارسة

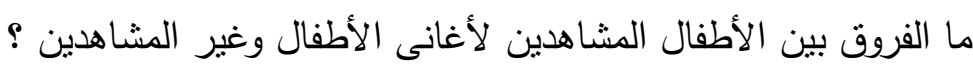

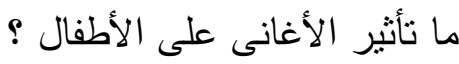

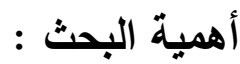
جاءت الحاجـة إلى إجراء هذه الدراسـة من أجلـل إلقاء الضوء على بعض المهارات الإجتماعية لدى الطفل مثل مهارة التعاون ومهارة المشاركة ومهارة التواصل .

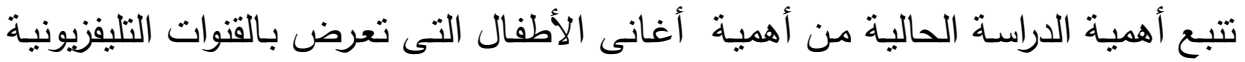
المتخصصة والتى تعمل على تتمية إتجاهاتهم الإجتماعية .

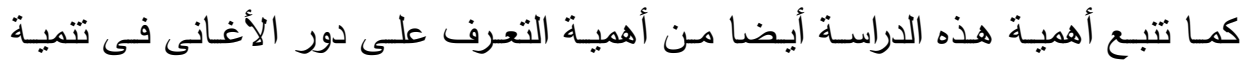

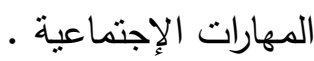
تستمد هذه الدراسة أهميتها من أهمية إكساب الأطفال بعض القيم والسلوكيات الإيجابية

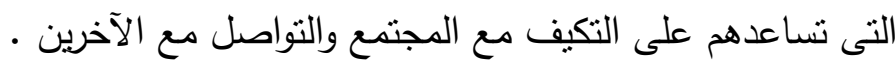


يهدف هذا البحث إلى التعرف على الدور الذى تقوم بـه أغانى الأطفال الدقدمة بالقنوات

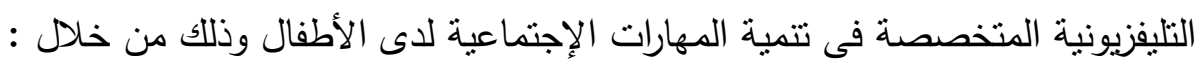
تحديد أكثر الأغانى التى تقيس بعض المهارات الإجتماعية .

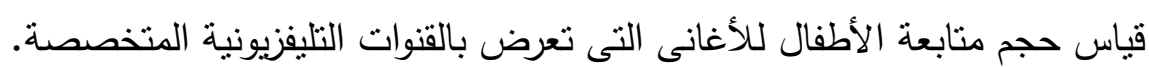

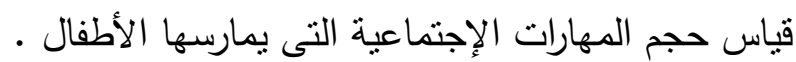

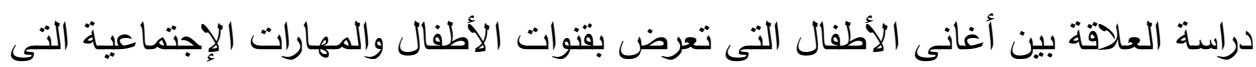
يكتسبها الطفل . دراسة أثز مشاهدة أغانى الأطفال على تتمية المهارات الإجتماعية .

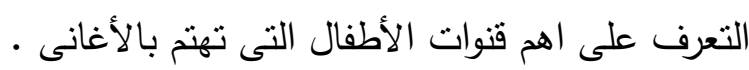
مصطلحات البحث : أغانى الأطفال : تعرف إجرائيا بأنها "أغانى سهلة وبسيطة تقدم للطفل بطريقة شيقة وجذابة

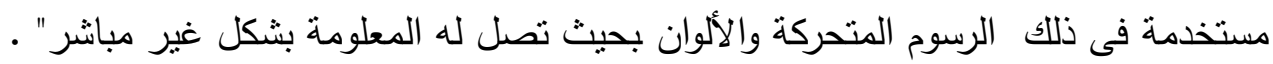

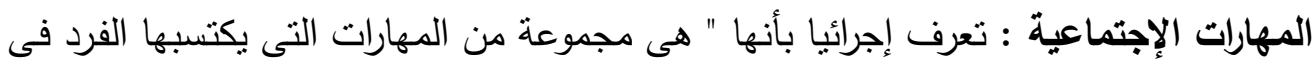

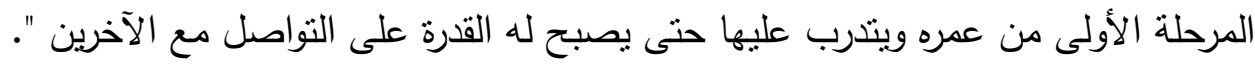

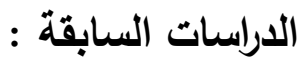
المحور الأول: الدراسات التي تناولت أغاني الأطفال :

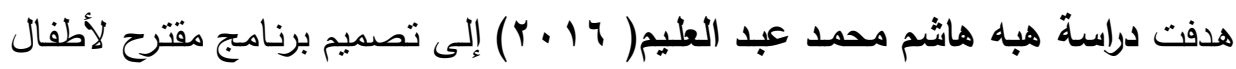

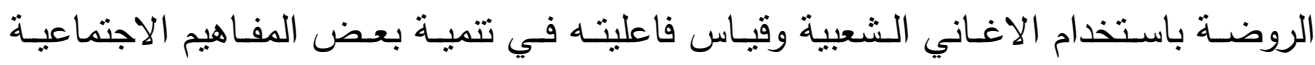

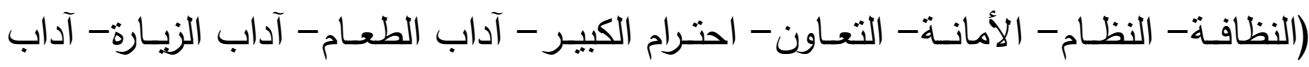

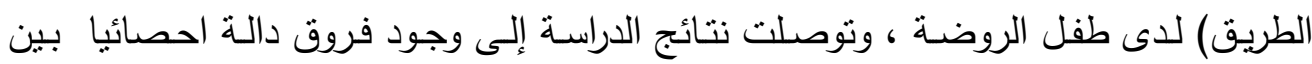

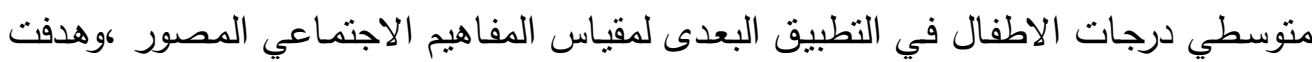

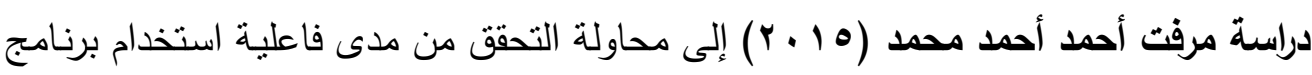

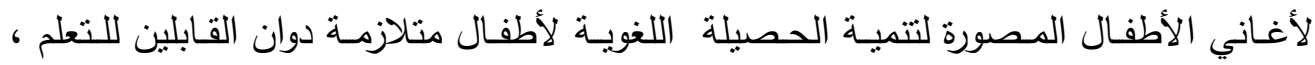

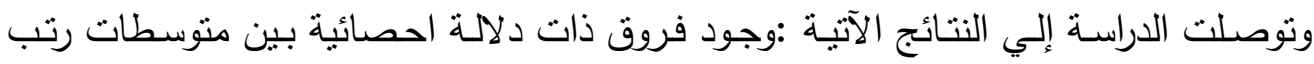

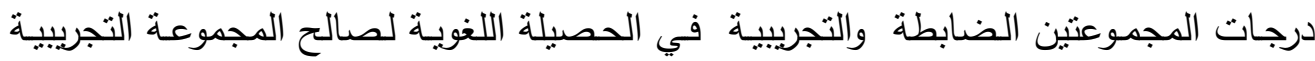

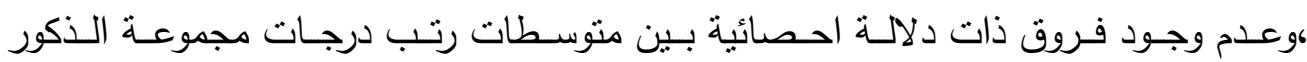

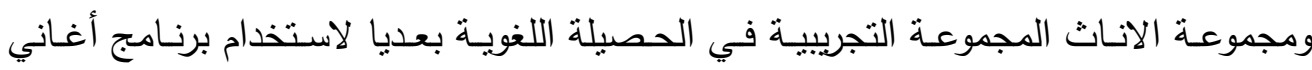

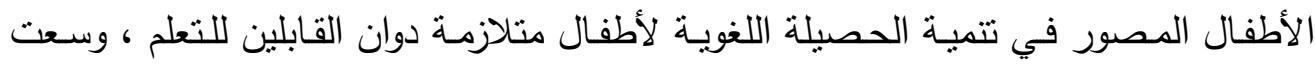


دراسة سحر سامى صلاح منصور ( ع 1 ـ ) ) إلى التعرف علي السلوكيات الحياتية الإيجابية

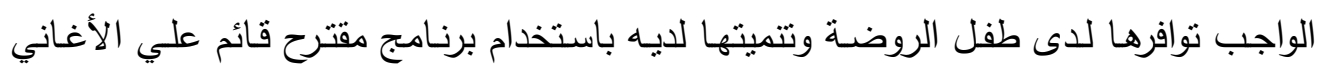

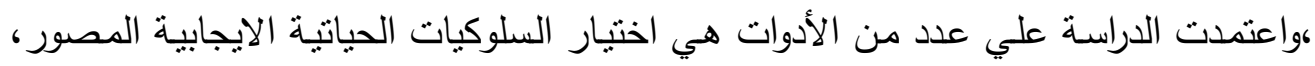

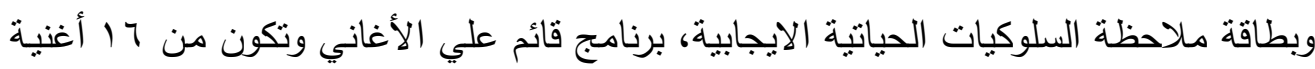

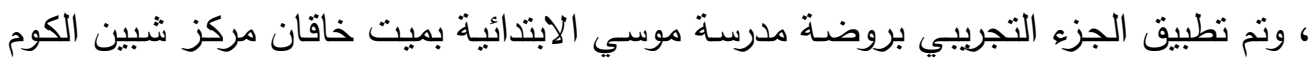

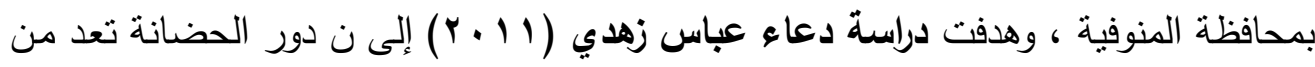

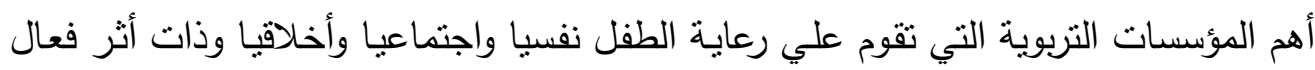

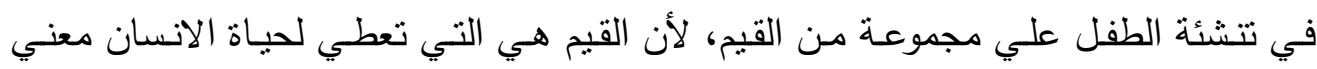

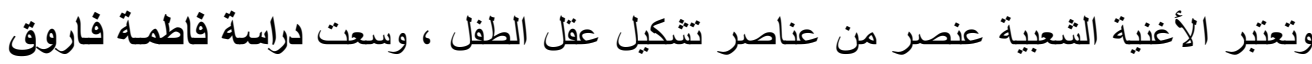

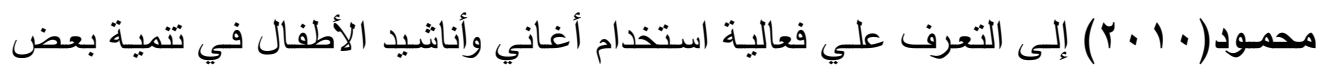
السلوكيات الاجتماعية التي تم تحديدها.

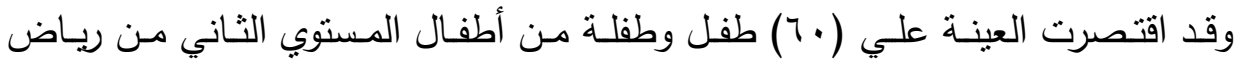

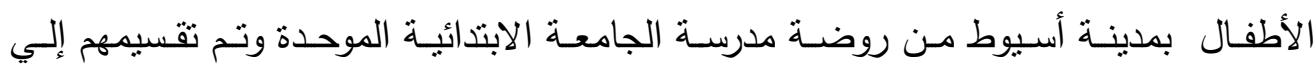

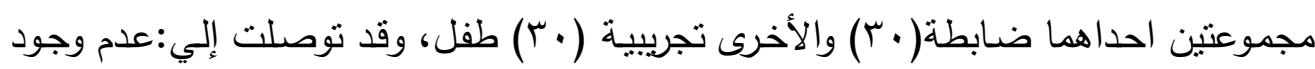

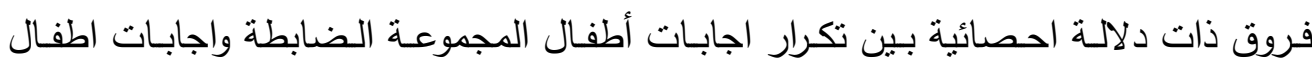

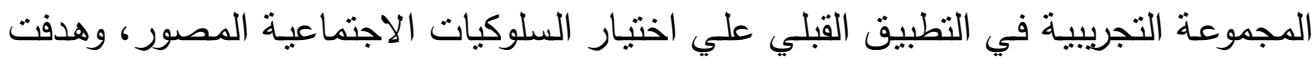

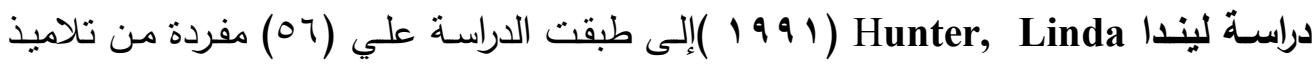

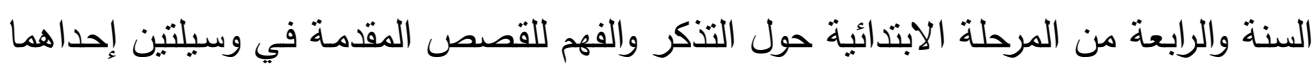

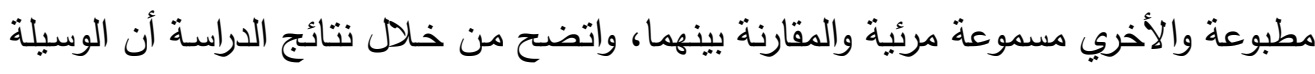

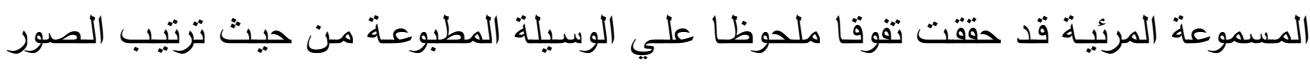

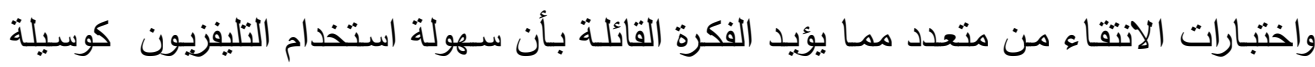
يمكن أن يحقق بعضا من الأداء الأفضل بالنسبة لبعض العضد العمليات العقلية.

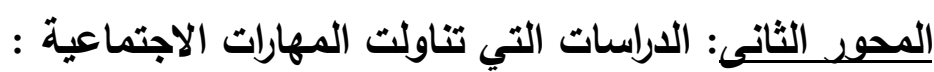

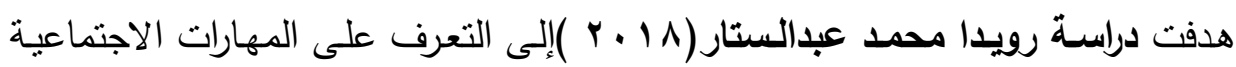

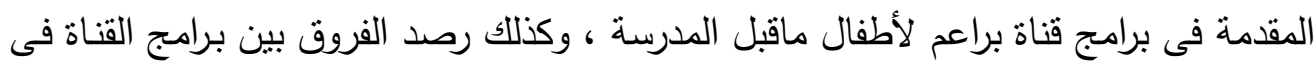

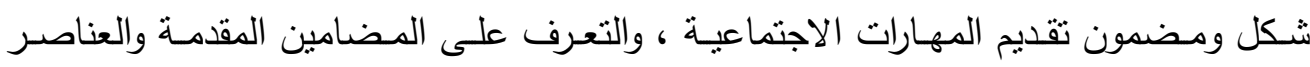

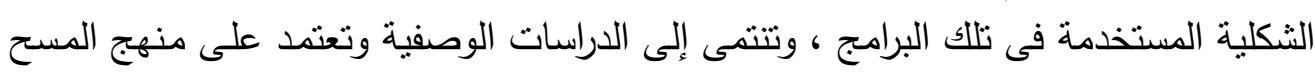

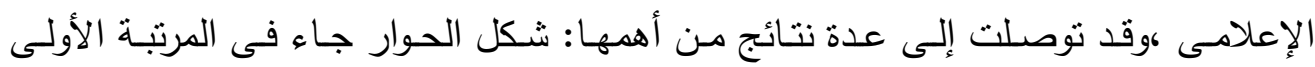

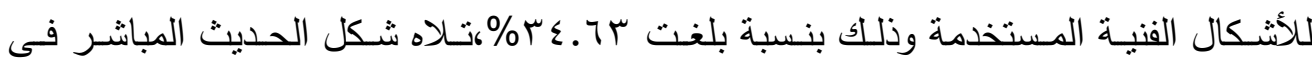

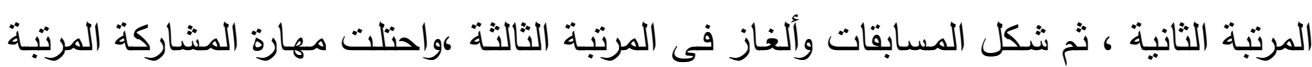




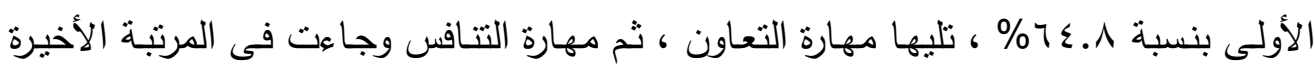

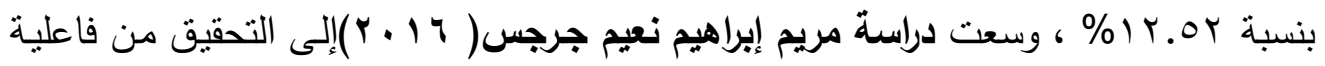

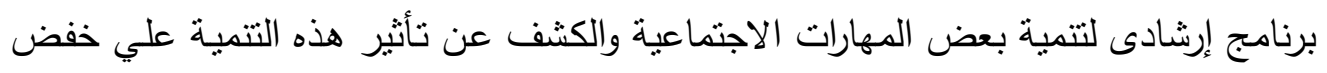

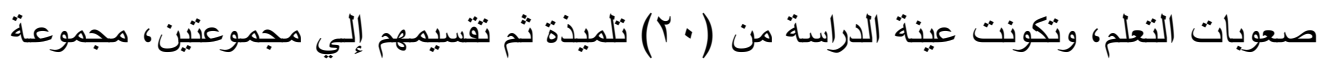

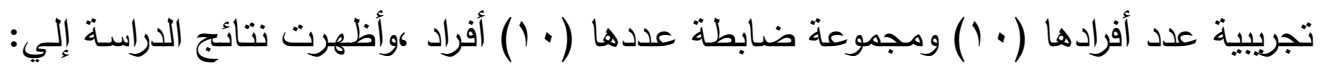

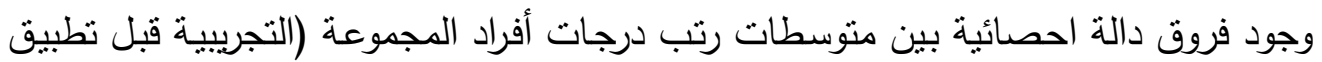

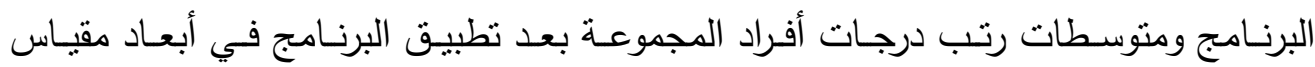

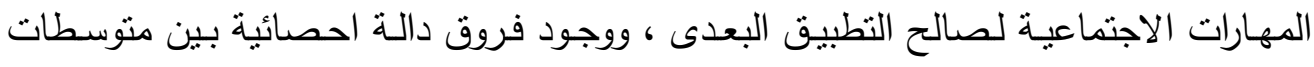

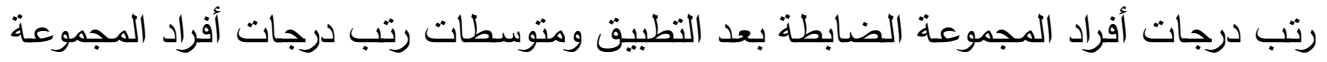

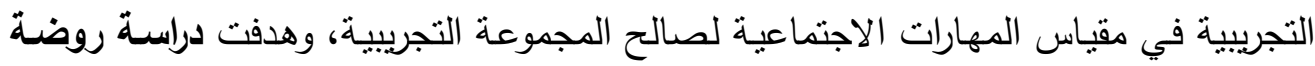

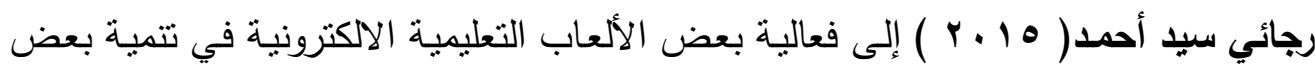

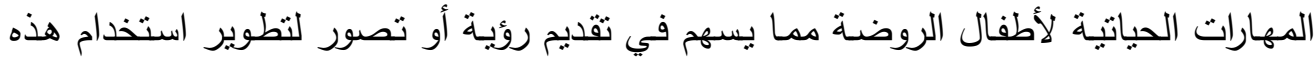

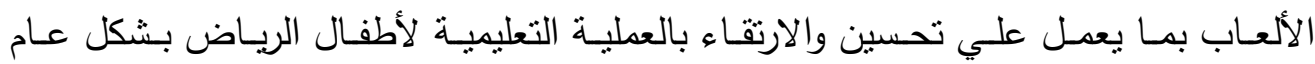

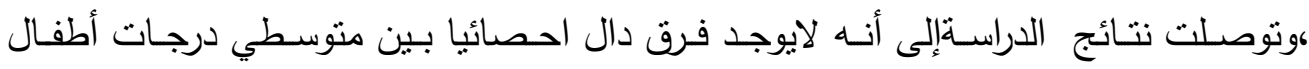

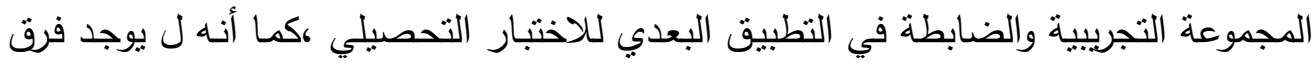

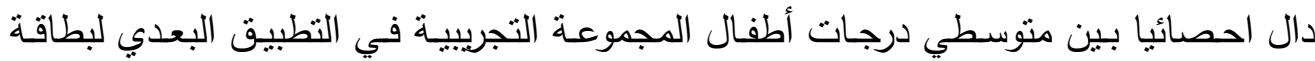

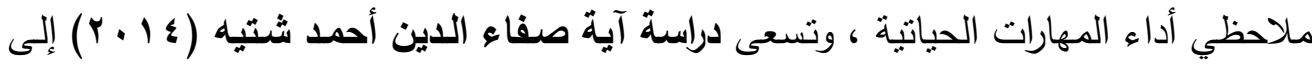

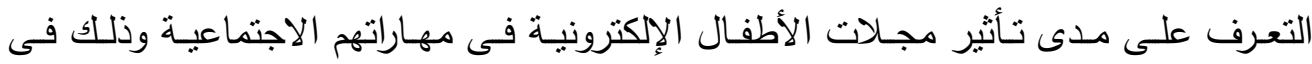

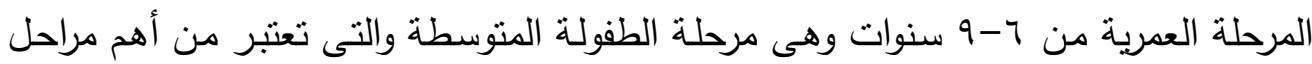

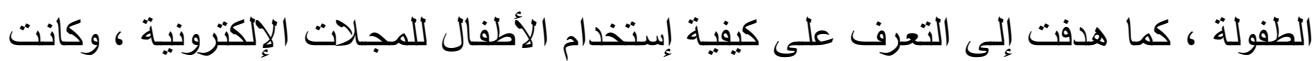

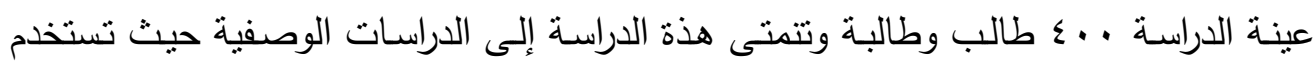

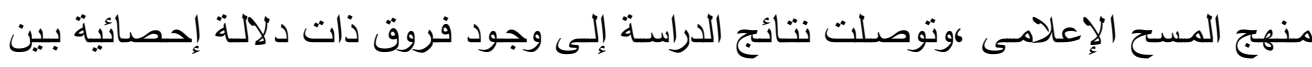

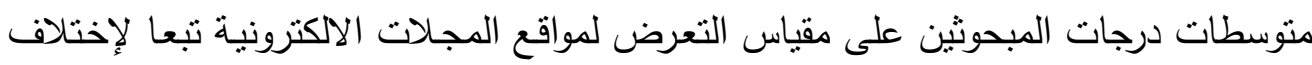

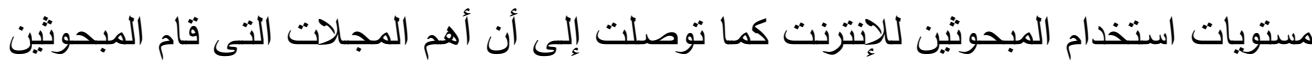

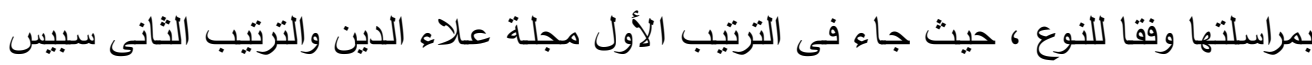

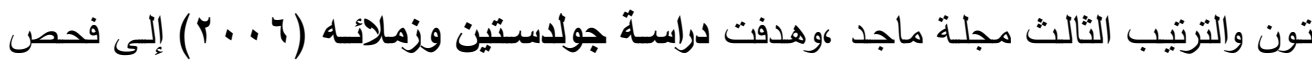

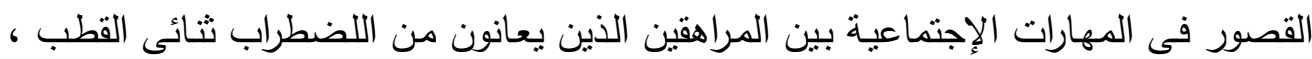

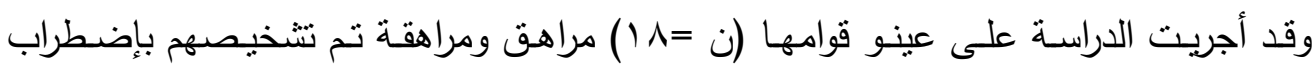

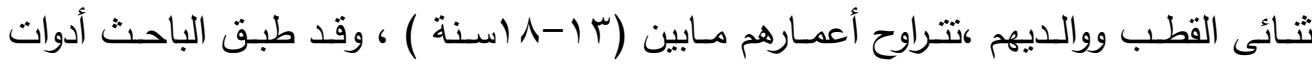

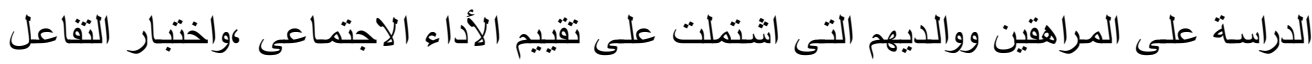

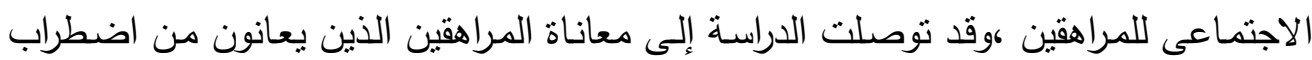

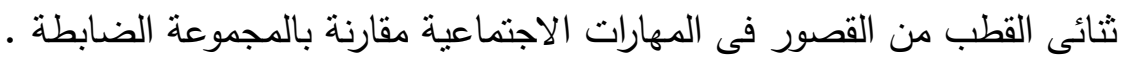




\section{أوجه الإستفادة من الاراسات السابقة :}

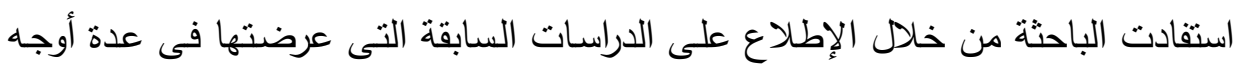

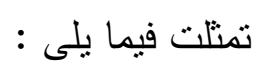

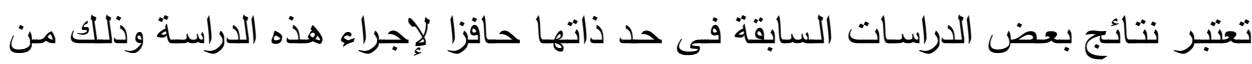
خلال الوقوف على أحدث النتائج التى توصل إلى إليها الباحثون السابقون .

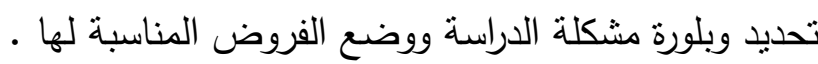

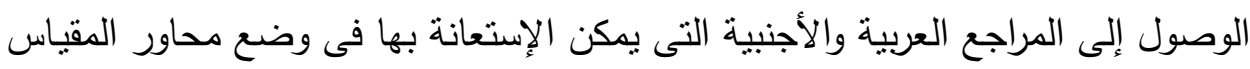

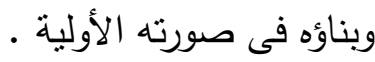
استفادت الباحثة من تلك الدراسـات في تحديد الدفاهيم الإجرائية للدراسـة وكذلك اختيار

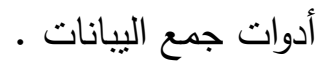

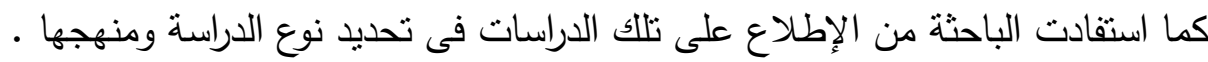
التعرف على أهم طرق المعالجة الإحصائية لقياس العلاقة بين متغيرات الدراسة . حدود البحث :

حدود موضوعية :حددت الباحثة موضوع دراستها فى التعرف على الدور الذى تقوم بـهـ

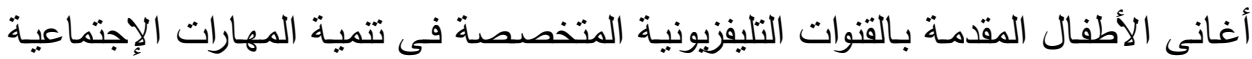

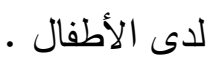

حدود بشرية : اقتصرت الدراسة على الأطفال فى المرحلة الإبتدائية من الذكور والإناث.

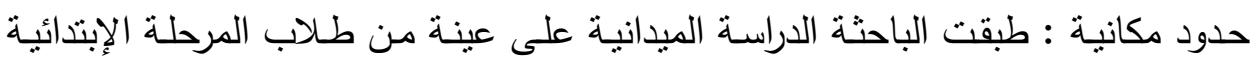

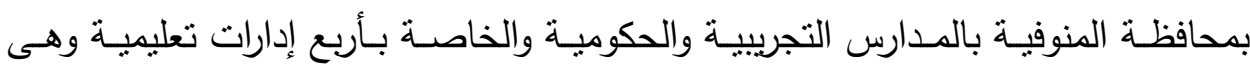

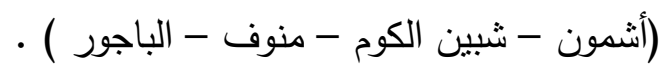

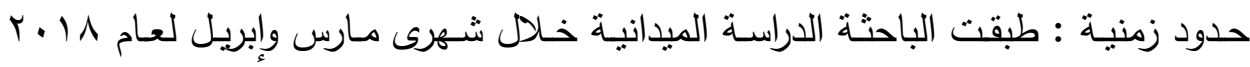

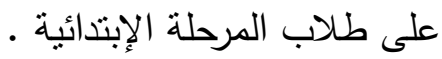
نوع ومنهج البحث:

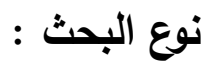

تتنمى هذه الدراسة إلى الدراسـات الوصفية ، حيث قامت الباحثة من خلاله بتوصيف

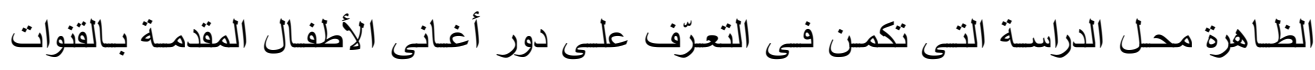

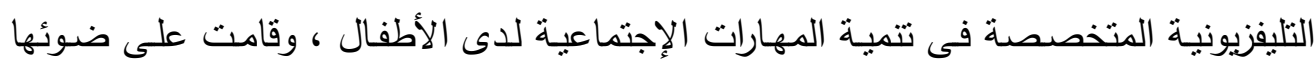

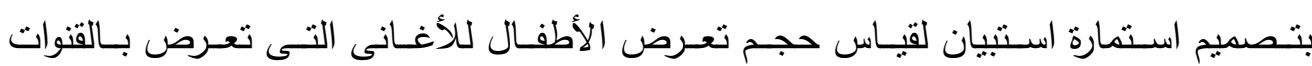
التلبفزيونية المتخصصة ، ومقياس لتحديد أهم المهارات الإجتماعية . 
اعتمدت الدراسة على منهج المسح ، حيث استخدمت الدراسـة المسح بالعينة لمجموعة الإسة

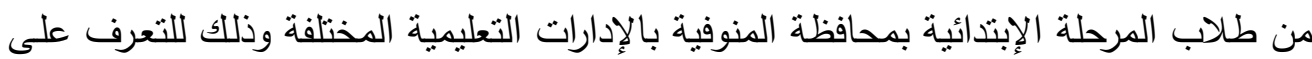
حجم مشاهدتهم للأغانى من ناحية ومستوى تتمية المهارات الاجتماعية لايهم من ناحية أخرى.

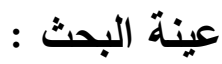

طبقت الدراسـة على عينـة عشوائية قوامها ( . . ـ) طالب وطالبة من الطلاب المرحلـة

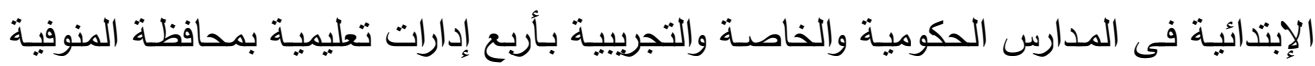

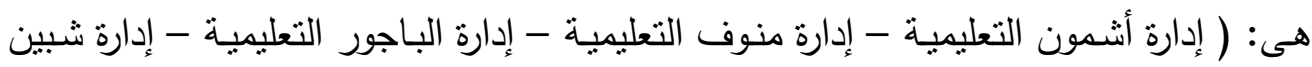

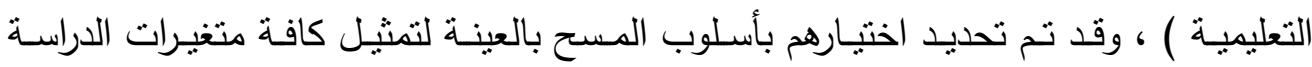

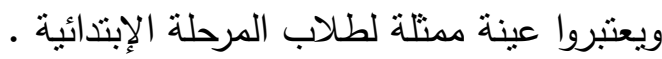

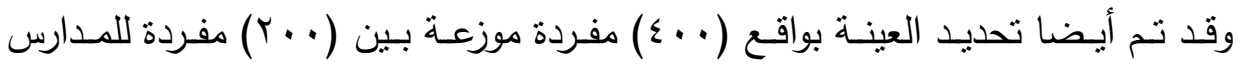

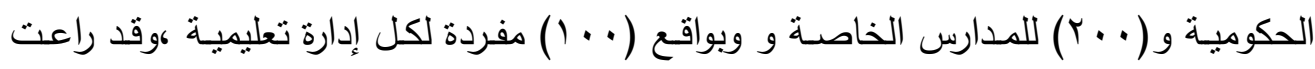

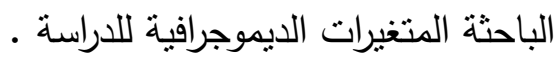
خطوات بناء مقياس المهارات الإجتماعية : المانية :

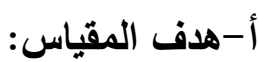
يهذف مقياس المهارات الإجنماعية إلي :

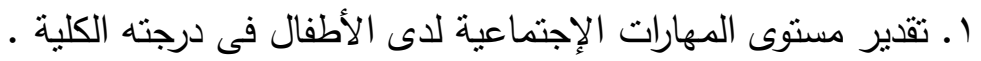

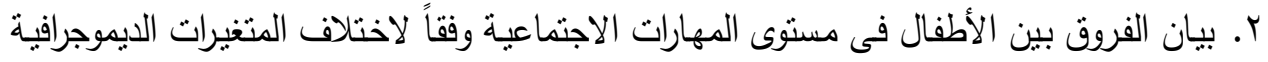

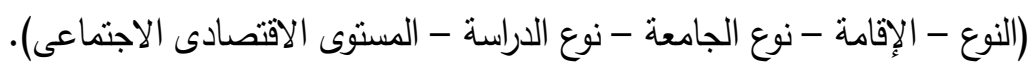

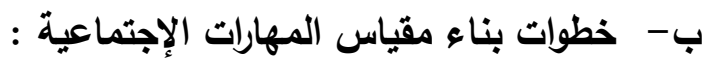

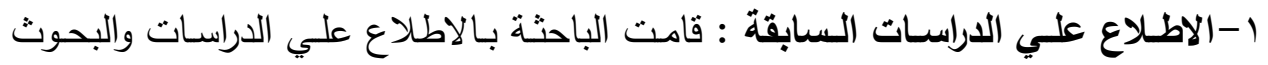

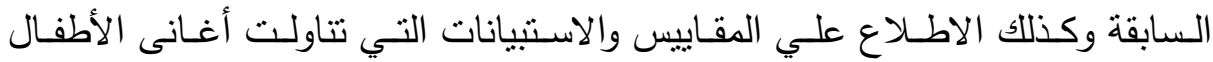
والمهارات الاجتماعبة المختلفة . وفي ضوء ذللك الاطلاع استعانت الباحثة في تصميم هذا المقياس بمصدرين أساسيين:

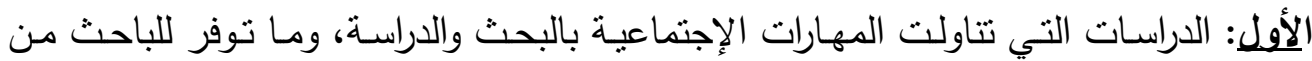

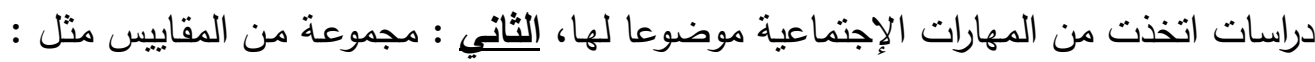

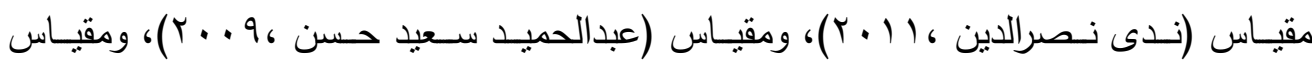

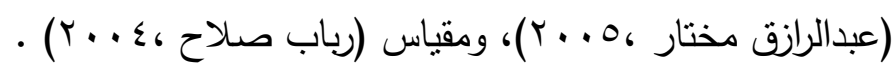

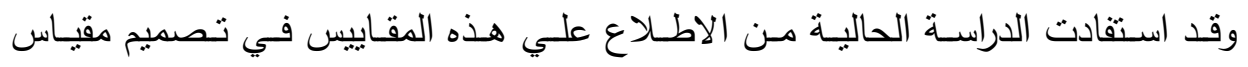
المهارات الإجتماعية الحالي وكيفية صياغة العبارات التي نلائم كل بعد من أبعاد المقياس. 
r-صياغة العبارات : إن صياغة عبارات المقياس أمر ينطلب الدقة والوضوح، فالنتائج قد

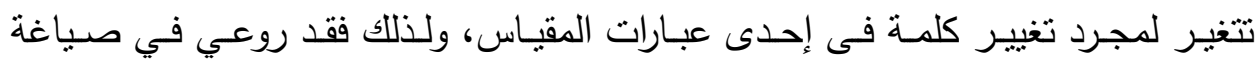
عبارات المقياس استخدام عبارات واضحة محددة المعنى، تخلو من المصطلحات الصعبة

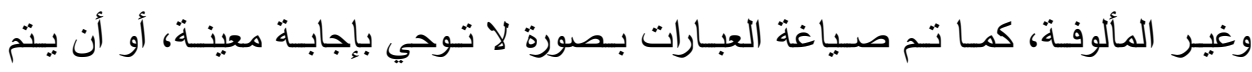

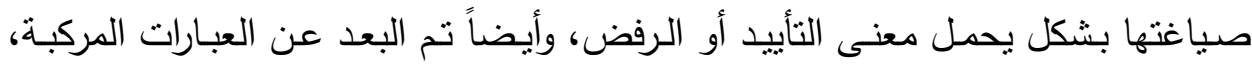
بحيث تضمنت كل عبارة من عبارات المقياس فكرة واحدة . ب-تحديد الاستجابات على المقياس: توجد أثنكال عديدة لصياغة العبارات وقد تم تحديد

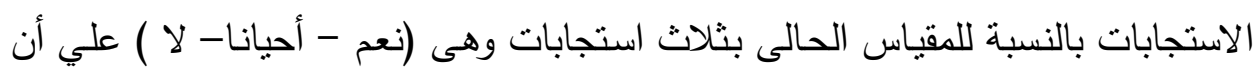
يكون تقدير هذه الاستجابات بإعطائها (1-r-r ) لكل عبارة ،ويتم ذلك من خلال اختيار

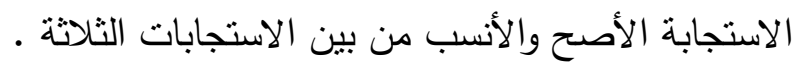

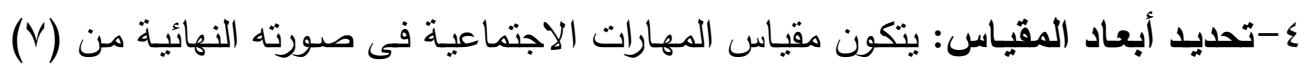

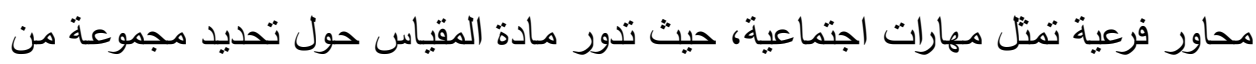

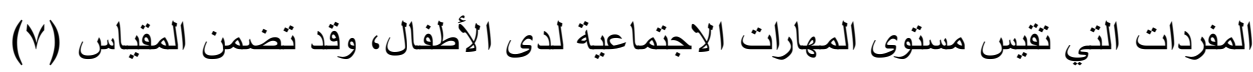
مهارات فرعيـة هي (مهارة التعـاون - مهارة المشاركة - مهارة آداب السلوك - مهارة النظافة مهارة الصدق - مهارة النظام - مهارة التواصل). ه-الحكم علي صلاحية المقياس: قامت الباحثة بعرض المقياس في صورته الأولية علي مجموعة من الخبراء والمحكمين في مجال علم الاجنماع والإعلام وعلم النفس والتربية بهدف إبداء الرأي في الجوانب التالية :التأكد من وضوح العبارات. مدى ارتباط المفردات بكل بعد من أبعاد المقياس .

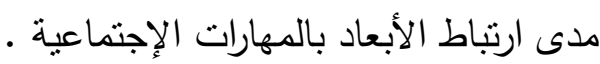
مدى صلاحية المقياس للأطفال في المرحلة الإبتدائية .

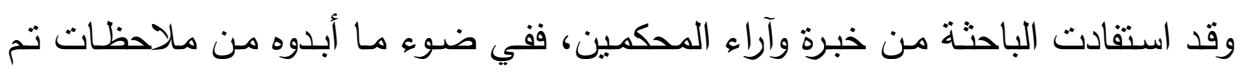

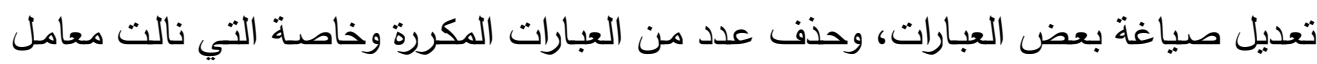
اتفاق أقل من ا9٪؛، وتعديل بعض المصطلحات في مفردات المقياس . 4-التجريب القبلي للمقياس: بعد صياغة عبارات المقياس قام الباحث بتجربته علي عينة

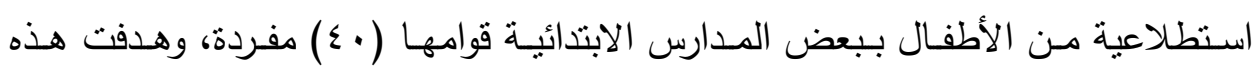


التجربـة إلي التعرف علي صـلاحية العبارات التي اتفق عليها المحكمون، واختبار مدى فهم الطلاب للألفاظ والأسلوب التي صيغت بـه عبارات المقياس، كما هدفت التجربة إلي التوصل إلي تقدير تقريبي للزمن الذي يستغرقه تطبيق المقياس، والاستقرار علي ترتيب العبارات قدر المستطاع. وكان من نتائج هذه التجرية:

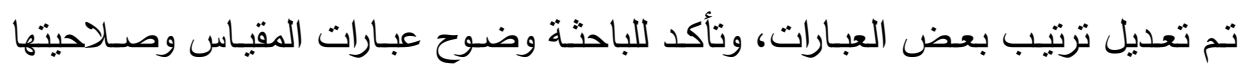
للاستخدام، كما تم حساب متوسط زمن التطبيق للمقياس بالنسبة للعينة المختارة، من خـال

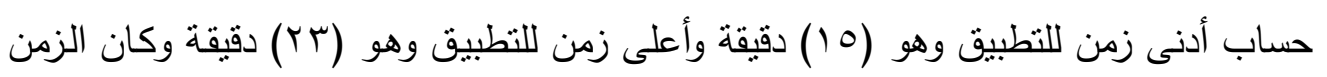
المتوسط 19 دقيقة، كما أسفرت التجربة عن قدرة المبحوثين علي فهم العبارات والتمييز بينها عند إلقائها عليهم لأول مرة دون استفسار عن معناها أو دلالتها.

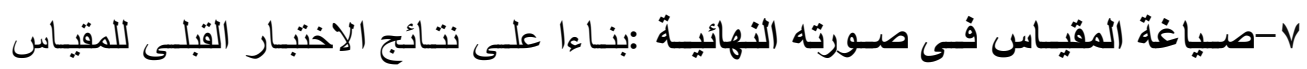
وملاحظات الخبراء والمحكمين تم صياغة المقياس فى شكله النهائى الذى تم تطبيقه على عينة الدراسة، ويتكون من (0) محاور ، ثم بعد ذلك قامت الباحثة بإجراء الدراسة الميدانية

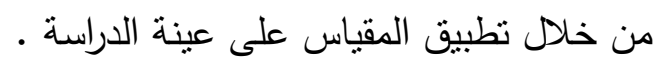
^- خطوات تقنين المقياس: أولاً: صدق المقياس:

يقصد بصدق الاختبار صحته في قياس ما يدعى انه يقيسه، والاختبار الصادق يقيس

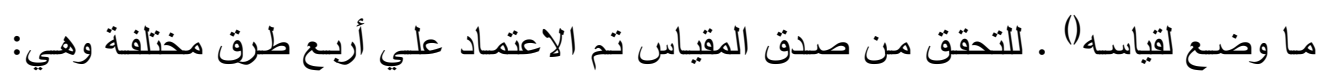

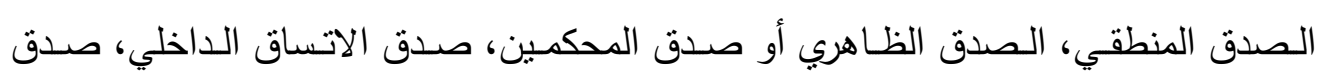
المقارنة الطرفية. أ- الصدق المنطقي (صدق المحتوى): اعتمدت الباحثة فى بناء هذا المقياس واختيار العبارات المكونة لأبعاده علي الدراسات

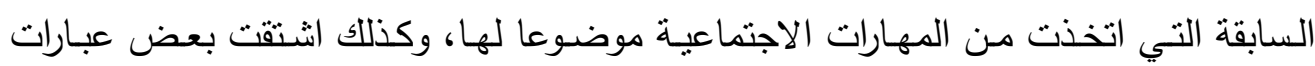

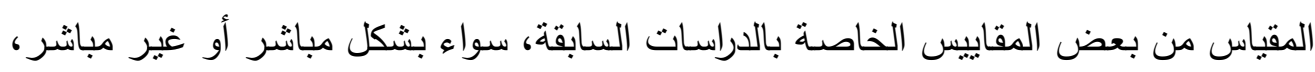

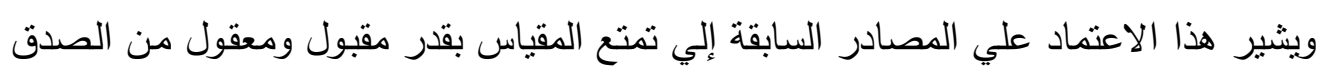
المنطقي وأن المقياس صالح للنطبيق. 


\section{ب- الصدق الظاهري أو صدق المحكمين :}

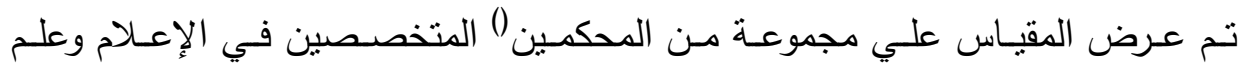

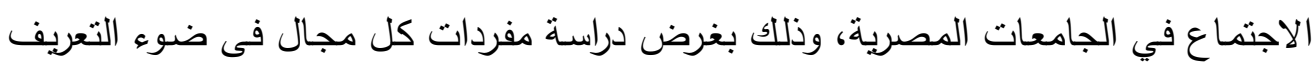
الإجرائي له، وكذلك الهيف من المقياس، وقد أقر المحكمون صلاحية المقياس بشكل عام بعد درداس إجراء بعض التعديلات التي إقترحها المحكمون، وقد تم الإبقاء على المفردات التى جاءت وهن

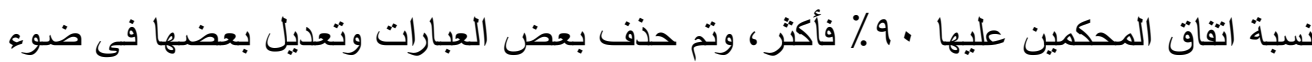
الملاحظات التى أبداها المحكمون ؛ حيث انتهى عدد العبارات إلى (ابها (ب) عبارة. ج- صدق الاتساق الاخلي :

تم حساب معاملات الارتباط بين درجة كل بعد من أبعاد مقياس المهارات الاجتماعية

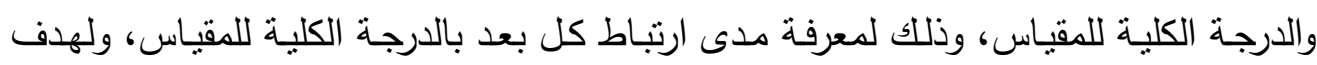
التحقق من مدى صدق المقياس، ويتضح ذللك من خلال جدول التالى. جدول(r)

معاملات الارتباط بين الدرجة الكلية لكل مقياس فرعى والدرجة الكلبة للمقياس

\begin{tabular}{|c|c|c|}
\hline مستوى الدلالة & معامل الارتباط & المهارات الاجتماعية \\
\hline دالة عند ا.... & . & مهارة التعاون \\
\hline دالة عند ا ... &.$V Y r$ & مهارة المشاركة \\
\hline دالة عند ا ... &. $.7 \wedge V$ & مهارة آداب السلوك \\
\hline دالة عند ا ... & . . & مهارة النظافة \\
\hline دالة عند ا ... & . Var & مهارة النظام \\
\hline دالة عند ا ... &. .170 & مهارة الصدق \\
\hline دالة عند ا... &. .771 & مهارة التواصل \\
\hline
\end{tabular}

د - الصدق التكوينى أو البنائى :

تم حساب الصدق البنائى أو التكوينى للمقياس وذلك عن طريق حساب معامل الارتباط بين درجة كل بند مع الدرجة الكلية للمقياس الفرعى لها بعد استبعاد قيمة هذا البند من الدرجة

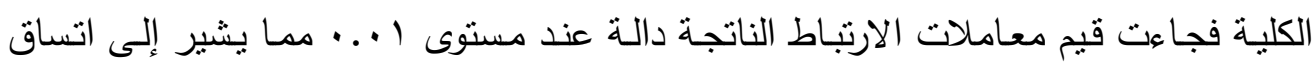

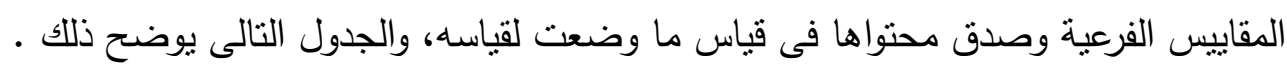
جدول (r) 
معاملات الارتباط بين درجات عبارات كل مقياس فرعى والدرجة الكلية للمقياس الفرعى لها

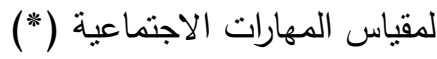

\begin{tabular}{|c|c|c|c|c|c|c|c|c|c|c|c|}
\hline & & & & & & & \multicolumn{5}{|c|}{ المهارات الفرعية للمقياس } \\
\hline \multicolumn{2}{|c|}{ مهارة الصدق } & \multicolumn{2}{|c|}{ مهارة النظام } & \multicolumn{2}{|c|}{ مهارة النظافة } & \multicolumn{2}{|c|}{ آداب السلوك } & \multicolumn{2}{|c|}{ 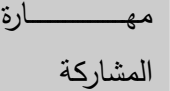 } & \multicolumn{2}{|c|}{ مهارة التعاون } \\
\hline 3) & $\frac{.9}{3}$ & $\frac{3}{3}$ & 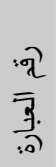 & $\frac{3}{3} \overline{7}$ & .9. & 章 & $\frac{9}{3.9}$ & 3. & : & $\frac{3}{3}$ & ?. \\
\hline..$\leqslant \vee 4$ & $r \varepsilon$ & Tr. & $r$. & .004 & 10 & $.7 \% 0$ & 11. &. $.7 \Lambda \varepsilon$ & &.$\leqslant 11$ & 1 \\
\hline .0 ro & ro & 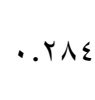 & r) & $.0 \leqslant 1$ & 17 & 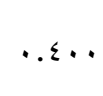 & 111 & .004 & & $\varepsilon 997$ & $r$ \\
\hline \multirow[t]{3}{*}{. Orr } & rq & $\cdot . \varepsilon \cdot r$ & rr & $\therefore$. ¿AV & iv & $\therefore$..११ & 114 &. .001 & & . & $r$ \\
\hline & & .7 .7 & r &..$\leqslant \wedge V$ & 11 &..$\leqslant 97$ & 111 & .. $\leqslant V V$ & &.$\varepsilon 9 \vee$ & $\varepsilon$ \\
\hline & & & & . . & 19 & $.0 Y \mathrm{~A}$ & $11 \varepsilon$ &. .291 & & & \\
\hline \multicolumn{12}{|c|}{ مهارة التواصل } \\
\hline & & 19 & & 7ו1 & . & re &..$\varepsilon$ & 09 & & $.0 \leqslant r$ & 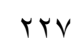 \\
\hline
\end{tabular}

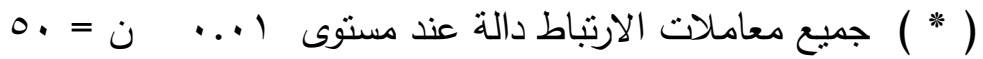

هـ - الصدق التمييزي (المقارنة الطرفية):

تعتمد هذه الطريقة في حساب صدق المقياس علي مقارنـة متوسط درجات الحالات

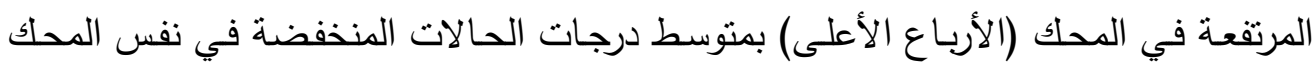

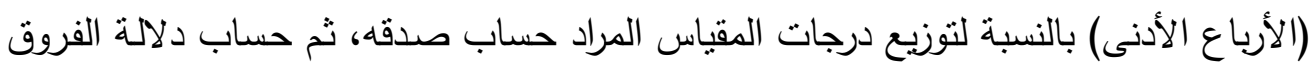
بين هذين المتوسطين ()، ولذا فقد تم حساب المتوسط والانحراف المعياري للدرجات الخـام الخاصـة بعينة التقنين. وفيما يلي جدول لبيان نتائج هذه المقارنة بالنسبة للارجة الكلية علي

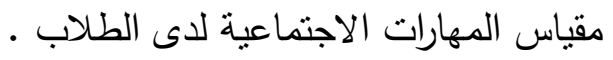




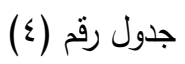

دلالة الفروق بين متوسط درجات الأرباع الأعلى والأدنى علي مقياس المهارات الاجتماعية

\begin{tabular}{|c|c|c|c|c|c|c|}
\hline مستوى الدلالة & ت & درجة الحرية & $\varepsilon$ & 5 & ن & المجموعة \\
\hline \multirow{2}{*}{ دالة عند } & \multirow{2}{*}{$1 . . v 1$} & \multirow{2}{*}{$\varepsilon \wedge$} & 9.14 & 174.11 & ro & الأرباع الأعلى \\
\hline & & & N.Tr & $1 \leqslant r . .0$ & ro & الأرباع الأدنى \\
\hline
\end{tabular}

تشير بيانات الجدول السابق إلى وجود فروق ذات دلالة إحصائية بين منوسطات درجات

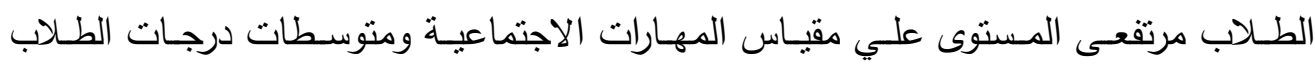

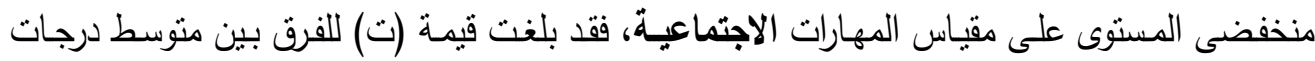

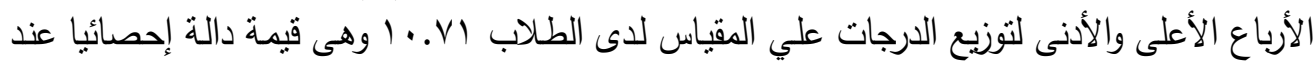

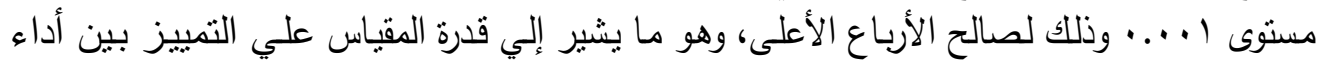

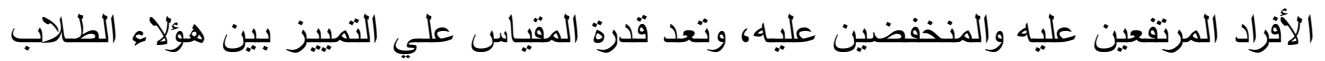

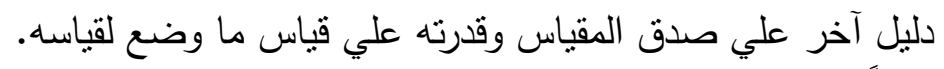

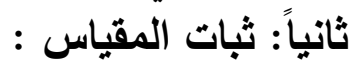

يقصد بثبات المقياس عادة أن تكون علي درجة عالية من الدقة والإتاتقان والاتساق فيما

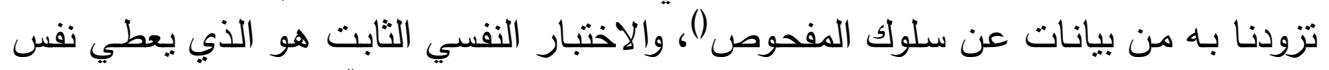

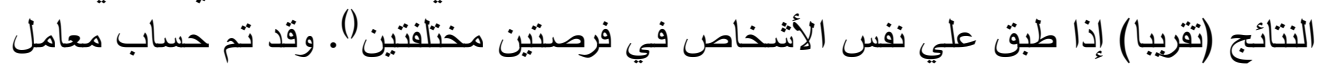

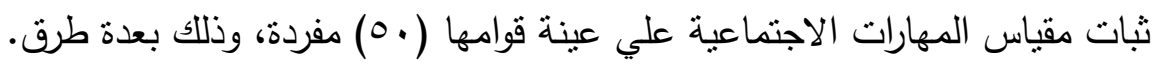
أ- طريقة إعادة التطبيق :

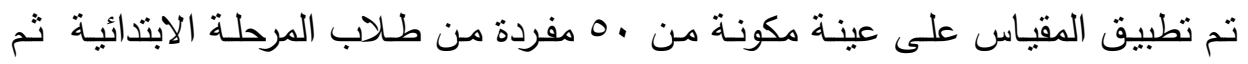

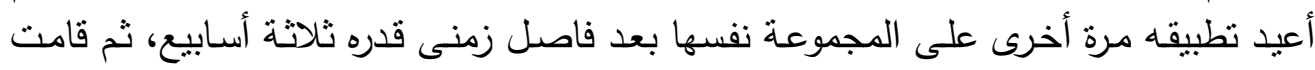

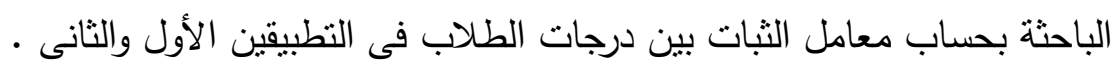

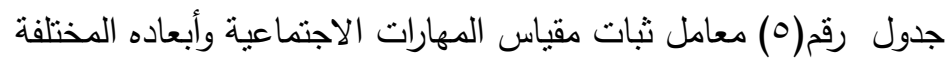

\begin{tabular}{|c|c|c|c|c|}
\hline مستوى الدلالة & معامل الثبات & عدد العبارات & البعد & 5 \\
\hline دالة عند ا ... & $\because \vee \vee 91$ & $\varepsilon$ & مهارة التعاون & 1 \\
\hline دالة عند ا ... & .Vro & 0 & مهارة المشاركة & r \\
\hline دالة عند ا ... & . . & 。 & مهارة آداب السلوك & $r$ \\
\hline دالة عند ا ... &. . ATr & 0 & مهارة النظافة & $\varepsilon$ \\
\hline دالة عند ا ... & ( & $\varepsilon$ & مهارة النظام & 0 \\
\hline دالة عند ا ... &. $.91 r$ & r & مهارة الصدق & 7 \\
\hline دالة عند ا ... & $\because \vee \wedge T$ & 0 & مهارة التواصل & $v$ \\
\hline دالة عند ا ... &.$A V Y$ & r & الدرجة الكلية & \\
\hline
\end{tabular}

يتضح من الجدول السابق مدى تقارب نسبة الثبات بين المجالات المختلفة، كما يتضح

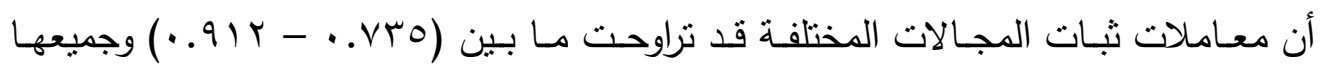


معاملات ثبات دالة عند مستوى ا ...، كما يبين أن معامل ثبات الدرجة الكلية للمقباس قد بلغ AVY. . وهي نسبة توحي بالثقة في صلاحية المقياس كأداة من أدوات الدراسة.

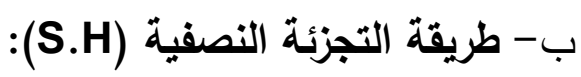
كما قامت الباحثة بحساب معامل ثبات كل بعد من أبعاد مقياس المهارات الاجتماعية،

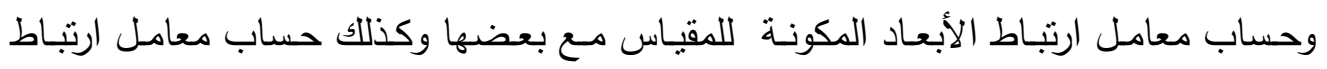

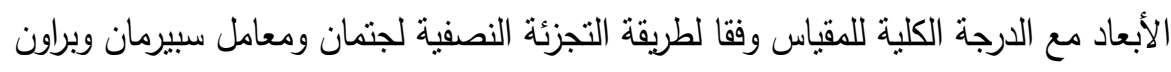
جدول رقم (7)

معامل ثبات مقباس المهارات الاجتماعية وأبعاده وفقا (التجزئة النصفية لجتمان- سبيرمان وبراون).

\begin{tabular}{|c|c|c|c|}
\hline سبيرمان - براون & معامــل ارتبــاط التجزئـــة & 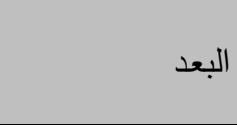 & \\
\hline..$\wedge V$ &. .14 & مهارة التعاون & 1 \\
\hline. .19 &. $.7 \mathrm{~V}$ & مهارة المشاركة & r \\
\hline$\therefore V \varepsilon$ &.$V 7$ & مهارة آداب السلوك & r \\
\hline r &..$\wedge \Lambda$ & مهارة النظافة & $\varepsilon$ \\
\hline$\therefore \vee 9$ &. .11 & مهارة النظام & 0 \\
\hline .91 &. .19 & مهارة الصدق & 7 \\
\hline.$\wedge \Lambda$ & . & مهارة التواصل & v \\
\hline
\end{tabular}

يتضح من الجدول السابق أن أبعاد مقياس المهارات الاجتماعية حققت معاملات ثبات علي درجة معقولة ومقبولة علمياً، حيث تراوحت معاملات ثبات المجالات وفقا لمعامل التجزئة

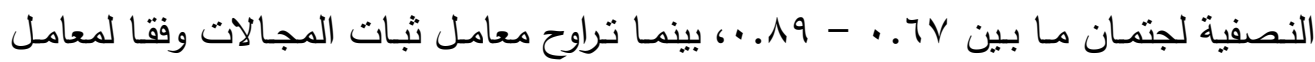

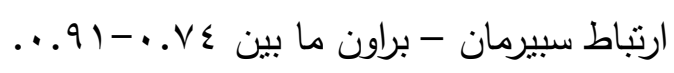

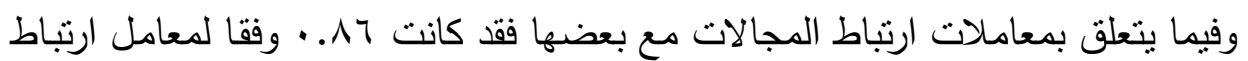

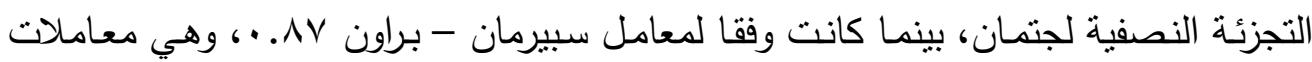
ثبات عالية وتدل علي ثبات المجالات.

وفيما يتعلق بمعاملات ارتباط المجالات مع الدرجة الكلية لمقياس المهارات الاجتماعية

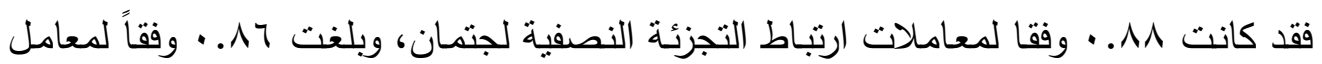
سبيرمان- براون وهي معاملات ثبات عالية وتشبر إلي ثبات المقياس وصلاحيته للاستخدام. 


\section{المعالجة الإحصائية للبيانات :}

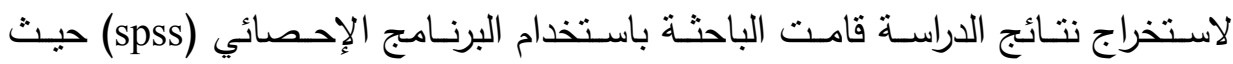

استخدمت بعض الأساليب الإحصائية التى تتلاعم وطبيعة البيانات المطلوبة البانية متل :

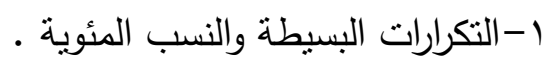

r-المتوسطات الحسابية والانحرافات المعيارية .

ب-تحليل التباين ذي البعد الواحد One Way Analysis of Variance ANOVA لدراسية

الفروق الإحصائية بين المتوسطات الحسابية للمجموعات في أحد متغيرات الدراسة.

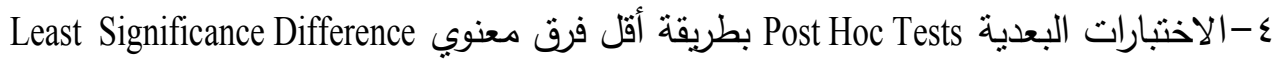

والمعروف بـ L.S.D لمعرفة مصدر التباين بين المجموعات التي يؤكد تحليل التباين علي

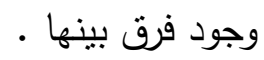

ه-معامل ارتباط بيرسون Pearson Correlation لدراسـة شدة واتجـاه العلاقة الارتباطيـة بين

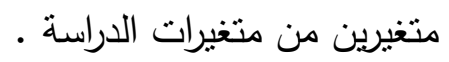

צ-اختبـار "ت" T.Test للمجموعـات المستقلة لدراسـة الفـروق بـين المنوسـطين الحسابيين

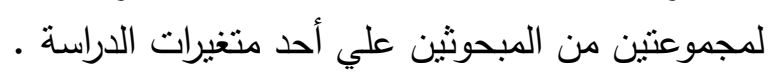

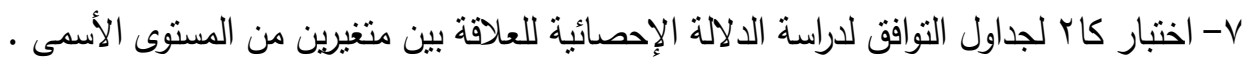

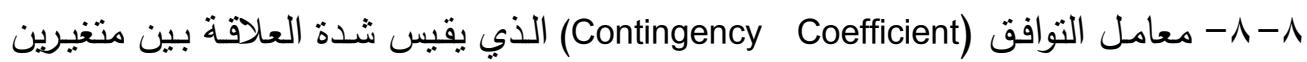

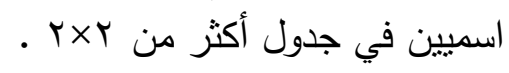

9-اختبار ". Z Test " لدراسة معنوية الفرق بين نسبتين مئوينين .

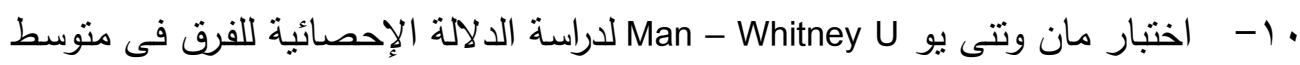

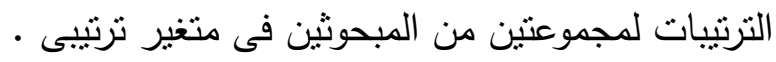

\begin{tabular}{|c|c|c|c|c|c|c|c|c|c|}
\hline \multirow{2}{*}{ 雪! } & \multirow{2}{*}{ الدلالة } & \multirow{2}{*}{ قيمة z } & \multicolumn{2}{|c|}{ الإجمالي } & \multicolumn{2}{|c|}{ إناث } & \multicolumn{2}{|c|}{ ذكور } & \multirow{2}{*}{ القنوات } \\
\hline & & & $\%$ & 5) & $\%$ & s) & $\%$ & ك & \\
\hline r & غير دالة & .9717 & $\{. .97$ & $10 \varepsilon$ & $\varepsilon \cdot, r\}$ & $V \varepsilon$ & $\sum 1.7 \mathrm{~V}$ & $\wedge$. & قناة طيور الجنة \\
\hline$r$ & غير دالة &.$\wedge V Y$ & ri.rs & 111 & $r \varepsilon . r \varepsilon$ & זי & rA.70 & 00 & قناة طيور بيبى \\
\hline 0 & غير دالة &. .911 & TY.TT & $1 . \varepsilon$ & หr.. 9 & $\varepsilon \wedge$ & rq.1V & 04 & قناة كراميش \\
\hline 1 & غير دالة & 1.940 & VY.AY & $r V \varepsilon$ & $79.0 \mathrm{~V}$ & IrA & Vฯ.. $\varepsilon$ & $1 \leq 4$ & قناة كوكى \\
\hline$\varepsilon$ & غير دالة & . Mro & YA.VY & $1 \cdot 1$ & $r q . \wedge 9$ & 00 & rV.T. & or & قناة مودى كيدز \\
\hline & & & \multicolumn{2}{|c|}{ rVY } & \multicolumn{2}{|c|}{$1 N \varepsilon$} & \multicolumn{2}{|c|}{194} & جملة من سئلوا \\
\hline
\end{tabular}

$$
\text { نتائج البحث وتفسيرها : }
$$

بالنسبة لأهم قنوات الأطفال المتخصصة وأفيرا : التى يفضل الأطفال متابعتها.

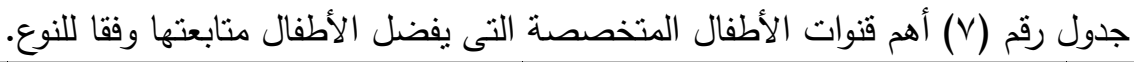


تشبر بيانات الجدول السابق إلى أهم قنوات الأطفال التتصصة التى يفضل الأطفال

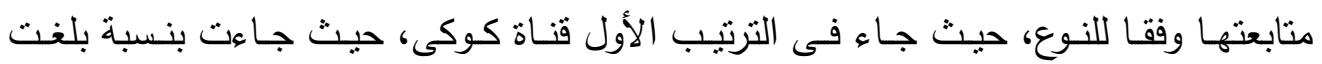
من \% م. NVV

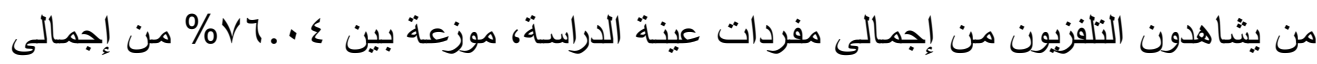

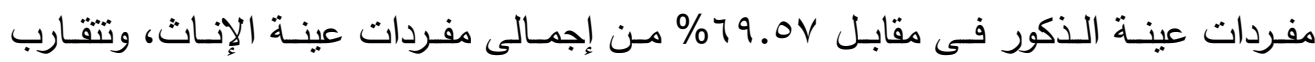

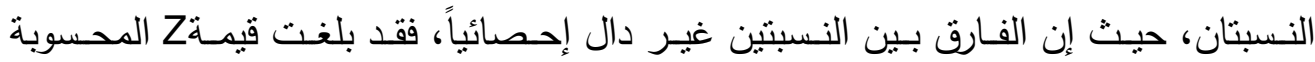

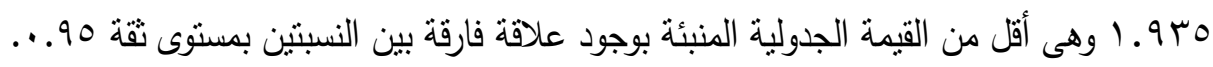

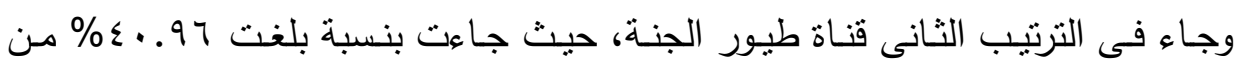
إجمالى مفردات من يشاهدون قنوات الأطفال المتخصصة من إجمالى مفردات من يشاهدون

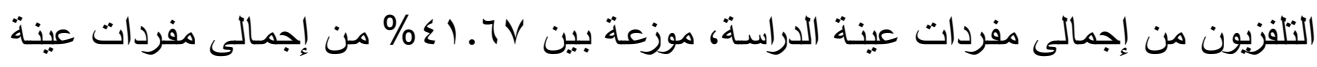

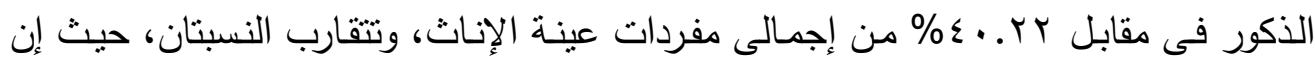

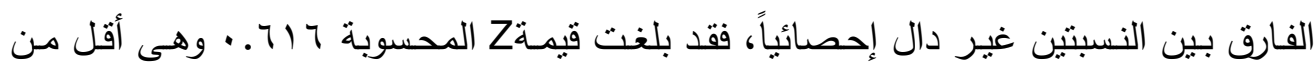
القيمة الجدولية المنبئة بوجود علاقة فارقة بين النسبتين بمستوى ثقة 90 هـ ـ.

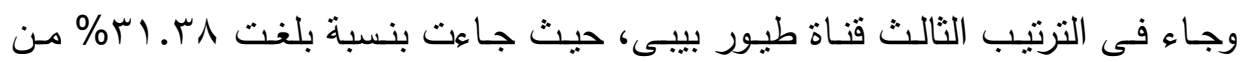
إجمالى مفردات من يشاهدون قنوات الأطفال المتخصصة من إجمالى مفردات من يشاهدون

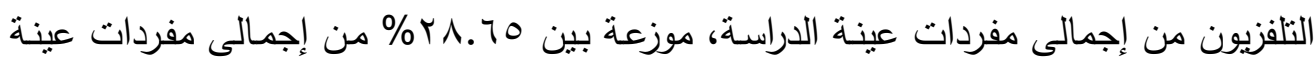

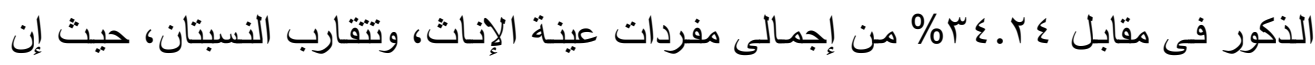

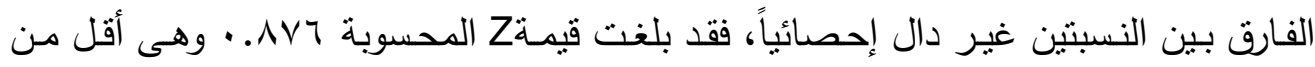
القيمة الجدولية المنبئة بوجود علاقة فارقة بين النسبتين بمستوى ثقة 90 . ..

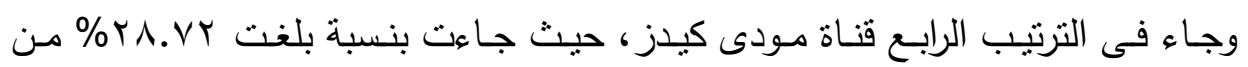
إجمالى مفردات من يشاهدون قنوات الأطفال المتخصصة من إجمالى مفردات من يشاهدون

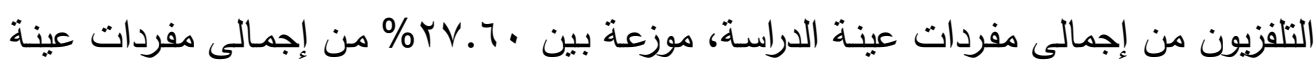

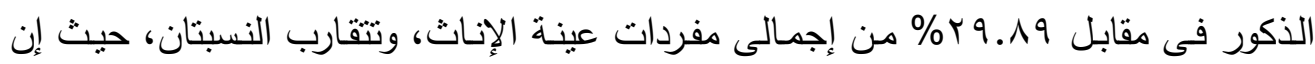

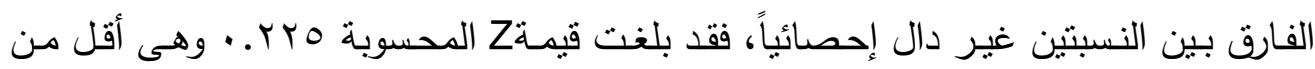
القيمة الجدولية المنبئة بوجود علاقة فارقة بين النسبتين بمستوى ثقة 90 . .

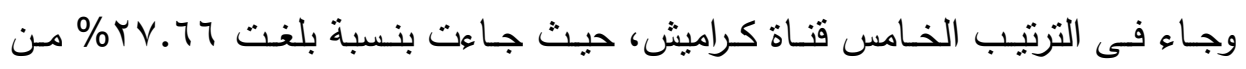
إجمالى مفردات من يشاهدون قنوات الأطفال المتخصصة من إجمالى مفردات من يشاهدون 


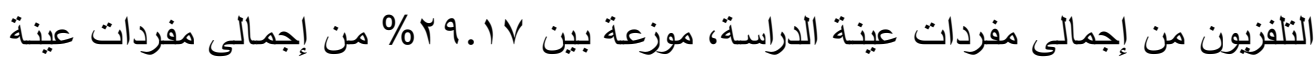

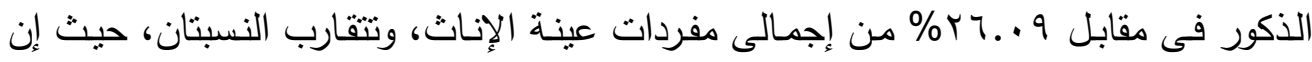

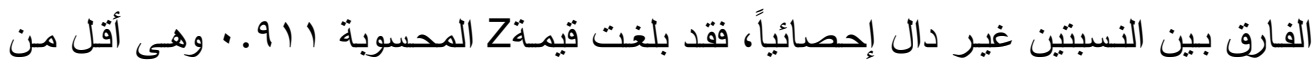
القيمة الجدولية المنبئة بوجود علاقة فارقة بين النسبتين بمستوى ثقة 90 ... r-استجابات المبحوثين على مقياس مهارة التعاون:

يبين الجدول التالى التكرارات والنسب المئوية والمتوسطات الحسابية لدرجة استجابات مهات مفردات عينة الدراسة على مقياس مهارة التعاون كأحد أبعاد المهارات الاجتماعية.

جدول (9) جانون

يوضح التكرارات والمتوسطات الحسابية لاستجابات المبحوثين على مهارة التعاون

\begin{tabular}{|c|c|c|c|c|c|c|c|c|c|c|}
\hline \multirow{2}{*}{ 争 } & \multirow{2}{*}{ 雪: } & \multirow{2}{*}{$\begin{array}{ll}\overline{7} & \overline{3} \\
\overline{9} & \overline{9}\end{array}$} & \multirow{2}{*}{$\overline{3} \frac{\overline{3}}{3}$} & \multicolumn{2}{|l|}{$y$} & \multicolumn{2}{|c|}{ أحبانا } & \multicolumn{2}{|c|}{ نعم } & \multirow{2}{*}{ العبارة } \\
\hline & & & & $\%$ & 5 & $\%$ & 5 & $\%$ & 5 & \\
\hline مرتفع & 1 &. .49 & T.A & 1.15 & $\varepsilon$ & $\mid T . \varepsilon \wedge$ & $\varepsilon \wedge$ & 10.49 & $r \cdot \varepsilon$ & 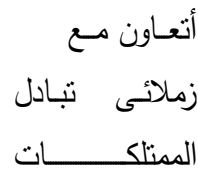 \\
\hline & & & & & & & & & & كالادوات \\
\hline مرتفع & $r$ & r.. & Y.Vq & .07 & $r$ & 19.77 & v. & $\vee \vee . \vee \wedge$ & YA & زملائكى دـاخل \\
\hline & & & & & & & & & & الفصل \\
\hline مرتفع & $\varepsilon$ & .01 & T.VI & 7.11 & r & 17.10 & 7. & VI. $9 \mathrm{~V}$ & $Y V \varepsilon$ & فريق أحب العمل فى \\
\hline مرتفع & $r$ & $\therefore \leqslant 9$ & Y.VA & r.rv & i & $10.1 \mathrm{~V}$ & 0\{ & $11 .\{4$ & rq. & طلب المساعد زميلي اذاة \\
\hline مرتنع & - &..$\leqslant V$ & r.VA & & & ن & 04 & & & التصميم ككل \\
\hline
\end{tabular}

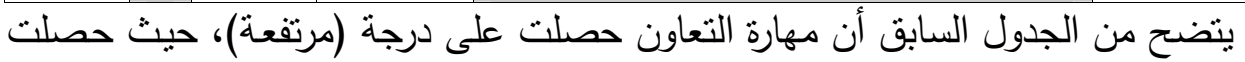

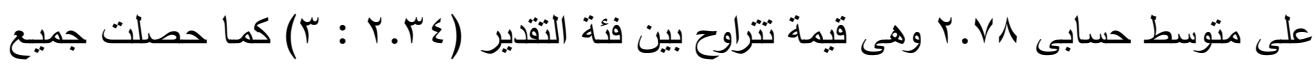

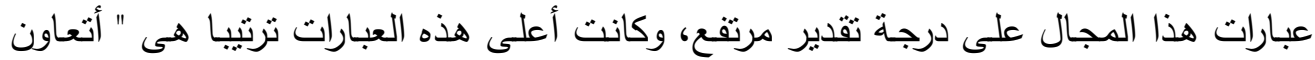

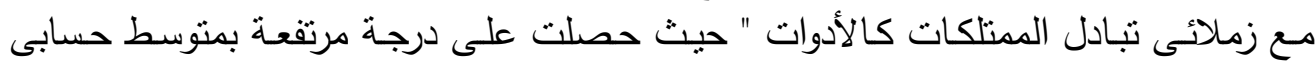

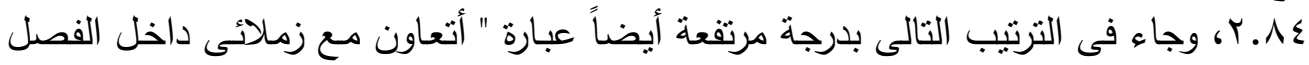

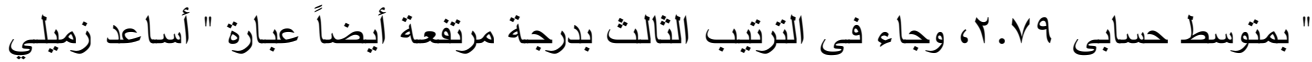

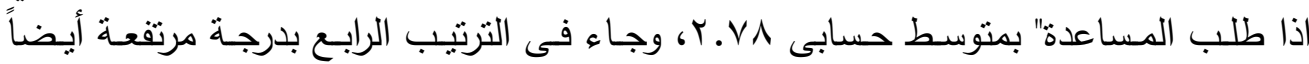

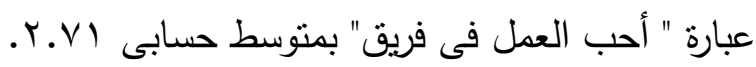




\section{ب-استجابات المبحوثين على مقياس مهارة المشاركة:}

يبين الجدول التالى التكرارات والنسب المئويـة والمتوسطات الحسابية لدرجة استجابات

مفردات عينة الدراسة على مقياس مهارة المشاركة كأحد أبعاد المهارات الاجتماعية.

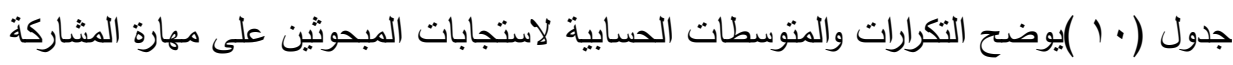

\begin{tabular}{|c|c|c|c|c|c|c|c|c|c|c|}
\hline \multirow{2}{*}{ 3. } & \multirow{2}{*}{ 裔! } & \multirow{2}{*}{$\begin{array}{ll}\overline{7} & \overline{3} \\
\frac{9}{9} & \overline{9}\end{array}$} & \multirow{2}{*}{$\begin{array}{ll}\overline{3} & \overline{7} \\
3 & \frac{3}{3} \\
\overline{7} & \end{array}$} & \multicolumn{2}{|c|}{ y } & \multicolumn{2}{|c|}{ أحيانا } & \multicolumn{2}{|c|}{ نعم } & \multirow{2}{*}{ العبارة } \\
\hline & & & & $\%$ & 5 & $\%$ & 5 & $\%$ & s) & \\
\hline | مرتفع & 0 & .71 & $r .01$ & 7.11 & rY & rq.vA & 1.4 & $T \varepsilon_{.} . \varepsilon$ & rYA & أشترك فى الأنثطة \\
\hline مرتفع & 1 & .00 & r.V. & $\varepsilon . \leqslant 9$ & 17 & r..ro & $V 4$ & $V \varepsilon .17$ & YTE & أقف مع أصدقائي \\
\hline مرتفع & $\varepsilon$ & .71 & r.TI & $7 . V \varepsilon$ & $Y \varepsilon$ & YO.A乏 & QY & $T V . \leqslant Y$ & $r \leqslant$. & أنترك فتى الرحلات \\
\hline | مرتفع & $r$ & •. $\leqslant \wedge$ & T.TE & $\cdots$ & . & ro.97 & 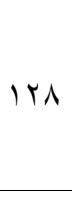 & $T\left\{. . \varepsilon^{\prime}\right.$ & YYA & مشاعرهم فى الحزن \\
\hline | مرتفع & r & .71 & T.TV & $V . \wedge V$ & YA & 17.10 & 7. & VO.YA & rat & أشارك اصدقائى فى \\
\hline | مرتفع & - &. $.0 \mathrm{~V}$ & r.T\& & & & & & & & التصميم ككل \\
\hline
\end{tabular}

يتضح مـن الجدول السابق أن مهارة المشاركة حصلت على درجـة (مرتفعـة)، حيث

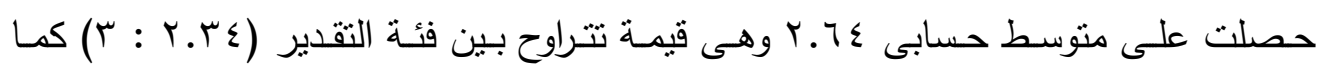
حصلت جميع عبارات هذا المجال على درجة تقدير مرتفع، وكانت أعلى هذه العبارات ترتيبا

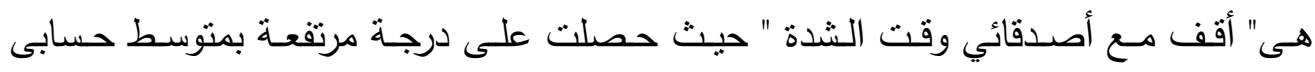
. وجاء فى V. .

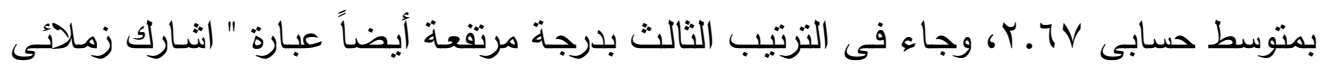

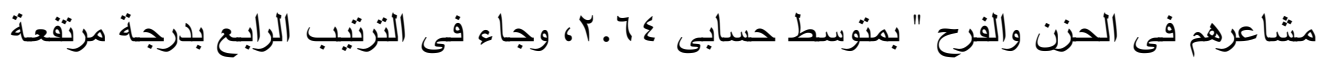

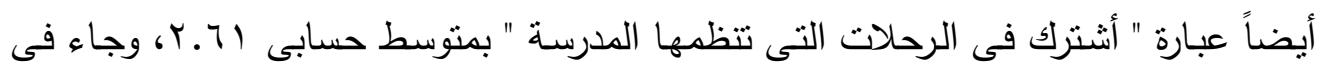

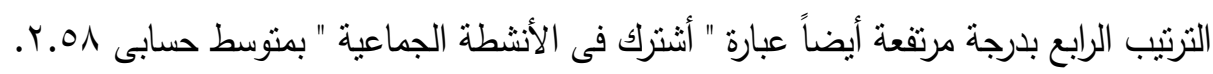




\section{ع-فيما يتعلق استجابات المبحوثين على مقياس مهارة آداب السلوك:}

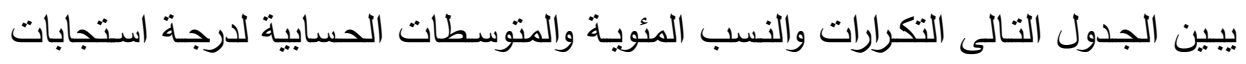

مفردات عينة الدراسة على مقياس مهارة آداب السلوك كأحد أبعاد المهارات الاجتماعية.

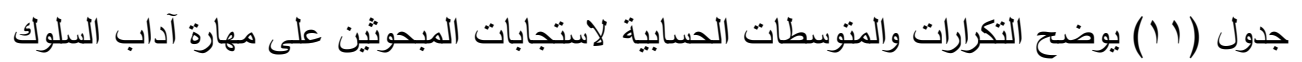

\begin{tabular}{|c|c|c|c|c|c|c|c|c|c|c|}
\hline $\begin{array}{l}3 \\
\overline{3} \\
: 0\end{array}$ & 高解 & $\begin{array}{ll}\bar{x} & \overline{3} \\
\frac{3}{9} & \frac{3}{9}\end{array}$ & $\begin{array}{l}\overline{3} \\
\frac{3}{3} \\
\overline{3} \\
\frac{3}{3}\end{array}$ & $\%$ & ك & بانا & ك5 & $\%$ & 5) & العبارة \\
\hline مرتفع & $\varepsilon$ & $\therefore \leqslant \wedge$ & T.TV &. .07 & r & r..$\leqslant 7$ & $11 \%$ & $7 V .91$ & $r \leqslant Y$ & 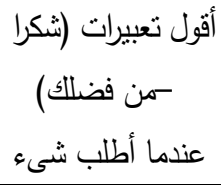 \\
\hline مرتقع & 0 & .09 & r.Or & 0.14 & 11 & rV.TE & $1 \pi \varepsilon$ & ov.r. & $r \cdot \varepsilon$ & لا أتحدث أثثاء \\
\hline مرتفع & 1 &..$\leqslant r$ & r.AI & 1.14 & $\varepsilon$ & 17.10 & 7. & VY.T. & TTY & أمتتع عن الغش فى الامتحان \\
\hline مرتفع & $r$ &..$\leqslant 9$ & r.Vq & T.94 & $1 \varepsilon$ & $1 \mathrm{r.qT}$ & $\leqslant 7$ & Nr.10 & Y97 & لا لاؤذى زملائى \\
\hline مرتفع & $r$ & .00 & T.V & $0 . \pi T$ & r. & $\mid \leq .71$ & or & 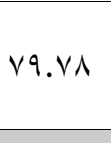 & Y^乏 & زلا أخذ شيئًا من \\
\hline مرتفع & - & .01 & r.VI & \multicolumn{6}{|c|}{ =ن } & التصميج ككل \\
\hline
\end{tabular}

يتضح من الجدول السابق أن مهارة آداب السلوك حصلت على درجة (مرتفعة)، حيث

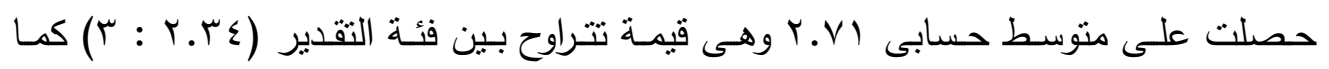

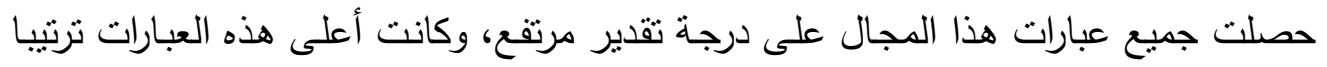

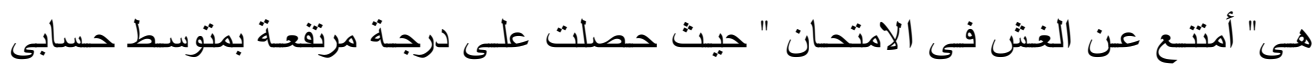

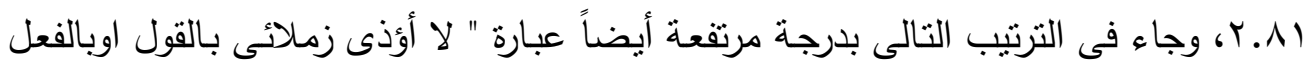

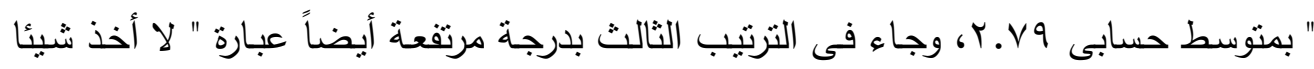

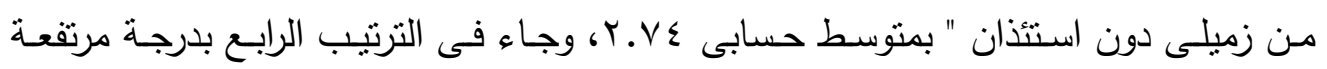

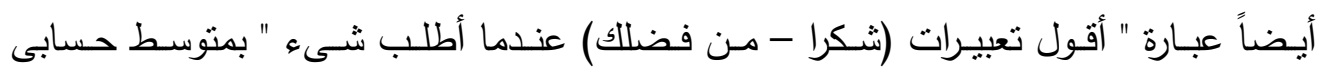

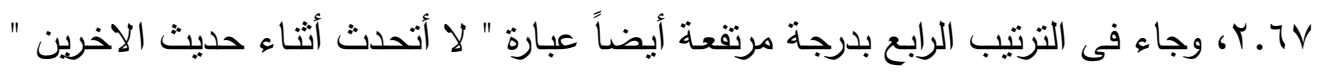

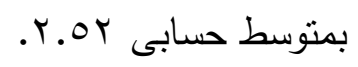




\section{ه- استجابات المبحوثين على مقياس مهارة النظافة:}

يبين الجدول التالى التكرارات والنسب المئويـة والمتوسطات الحسابية لدرجة استجابات مفردات عينة الدراسة على مقياس مهارة النظافة كأحد أبعاد المهارات الاجتماعية. جدول (r) (1):يوضح النكرارات والمتوسطات الحسابية لاستجابات المبحوثين على مهارة النظافة

\begin{tabular}{|c|c|c|c|c|c|c|c|c|c|c|}
\hline \multirow[b]{2}{*}{. } & \multirow[b]{2}{*}{ 高! } & \multirow{2}{*}{$\begin{array}{ll}\bar{\lambda} & \overline{3} \\
\frac{3}{9} & \frac{1}{9}\end{array}$} & \multirow{2}{*}{$\begin{array}{ll}\overline{3} & \overline{7} \\
3 & 3 \\
7 & 3\end{array}$} & \multicolumn{2}{|c|}{ y } & \multicolumn{2}{|c|}{ أحيانا } & \multicolumn{2}{|c|}{ نعم } & \multirow[b]{2}{*}{ العبارة } \\
\hline & & & & $\%$ & 5 & $\%$ & 5 & $\%$ & ك & \\
\hline مرتفع & $r$ & .. & r.V9 & $\ldots$ & $\cdot$ & $r . . v q$ & $V \varepsilon$ & V..YI & TAY & نظافة مظهرى على \\
\hline مرتفع & 0 &. .01 & T.OV & .07 & r & ET.IT & 10. & Or.r. & $r \cdot \varepsilon$ & نظافة الفصل على \\
\hline مرتفع & $\varepsilon$ & .07 & T.TY & T.9T & $1 \varepsilon$ & rq.vA & 1.7 & 74.19 & דוr & لا أقوم بإلقاء \\
\hline مرتفع & 1 &..$r$ & r.97 & $\cdots$ & $\cdot$ & $\varepsilon . \leqslant 9$ & 17 & 90.01 & $r \varepsilon$. & ملابسى دائما \\
\hline مرتفع & r & $\therefore$. & r.A. & $\cdots$ & $\cdot$ & $r . . r T$ & VY & V৭.vA & Y^乏 & لأكتب على الجدران \\
\hline مرتفع & - &.$\leqslant Y$ & r.vo & & & r & & & & التصميم ككل \\
\hline
\end{tabular}

يتضح من الجدول السابق أن مهارة النظافة حصلت على درجة (مرتفعة)، حيث حصلت

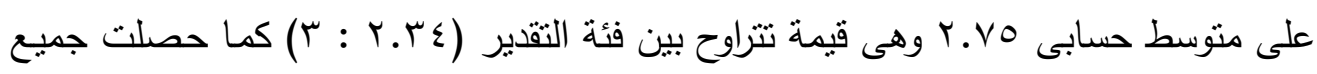

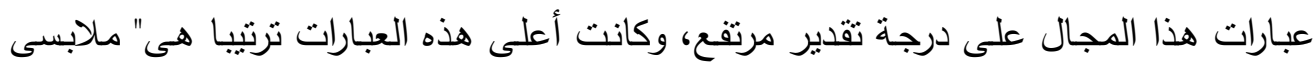

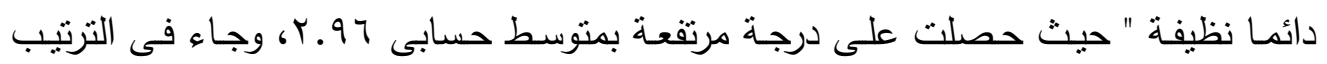

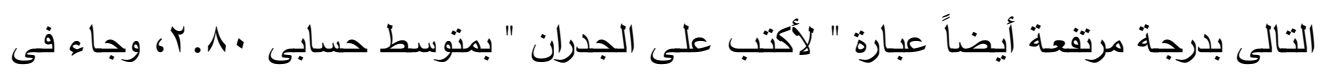

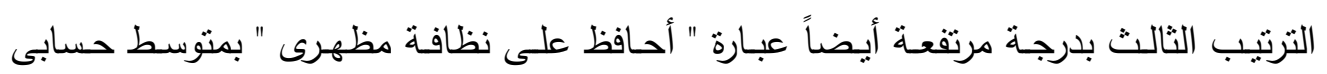

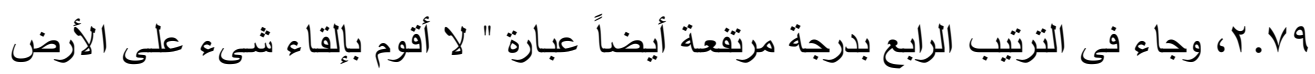

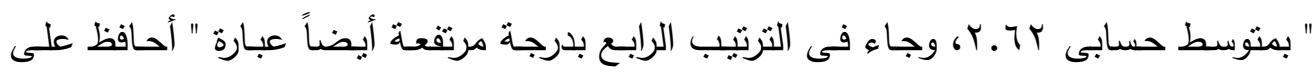
نظافة الفصل " بمتوسط حسابى Y.OV. 


\section{ج-استجابات المبحوثين على مقياس مهارة النظام:}

يبين الجدول التالى التكرارات والنسب المئويـة والمتوسطات الحسابية لدرجة استجابات مفردات عينة الدراسة على مقياس مهارة النظام كأحد أبعاد المهارات الاجتماعية.

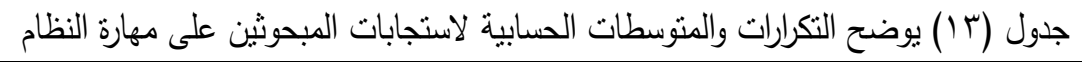

\begin{tabular}{|c|c|c|c|c|c|c|c|c|c|c|}
\hline \multirow{2}{*}{$\begin{array}{l}\overline{9} \\
\end{array}$} & \multirow{2}{*}{ 䨪! } & \multirow{2}{*}{$\begin{array}{ll}\overline{7} & \overline{3} \\
\frac{1}{9} & \frac{3}{9} \\
\end{array}$} & \multirow{2}{*}{$\begin{array}{ll}\overline{3} & \overline{7} \\
3 & \frac{3}{3} \\
\end{array}$} & \multicolumn{2}{|c|}{$y$} & \multicolumn{2}{|c|}{ أحيانا } & \multicolumn{2}{|c|}{ نعم } & \multirow{2}{*}{ العبارة } \\
\hline & & & & $\%$ & ك & $\%$ & s) & $\%$ & ك) & \\
\hline مرتفع & $r$ &..$\leqslant V$ & Y.VI & .07 & r & TY.OT & 91 & 51.91 & rot & 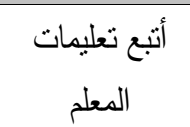 \\
\hline مرتفع & r & .0. & T.V & T.NI & 1. & $Y \cdot, Y Y$ & $V Y$ & $\mathrm{~V} 7.9 \mathrm{~V}$ & TVE & المدادبة إلى المى \\
\hline مرتفع & 1 & . & T.V9 & 1.14 & $\varepsilon$ & 19.1. & 71 & 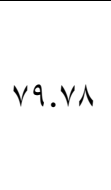 & rA $\varepsilon$ & أضع أدوات أماكنها في \\
\hline مرتفع & $\varepsilon$ & $\therefore \leqslant 9$ & Y.TV & $1.1 Y$ & $\varepsilon$ & $r . . T \varepsilon$ & 1.1 & $71.0 \leqslant$ & $r \leq \varepsilon$ & أطلب الأذن من \\
\hline مرتفع & - &..$\varepsilon V$ & r.VT & & & & & & & التصميم ككل \\
\hline
\end{tabular}

يتضح من الجدول السابق أن مهارة النظام حصلت على درجة (مرتفعة)، حيث حصلت

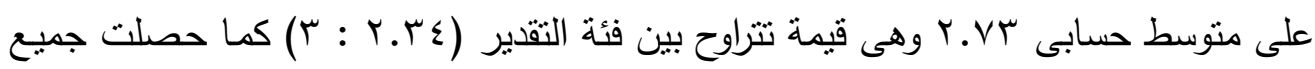

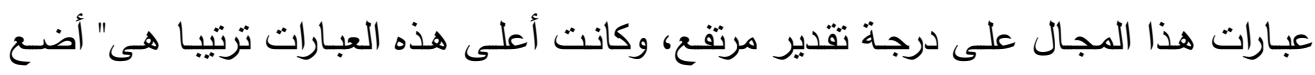

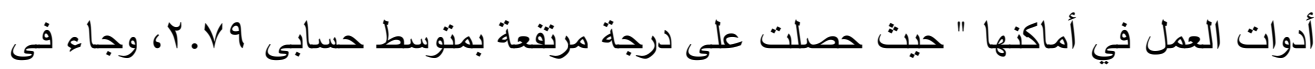

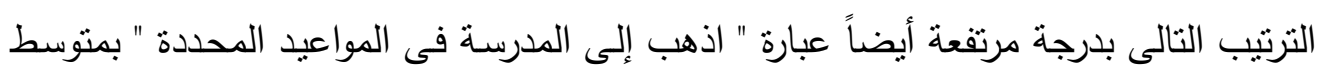

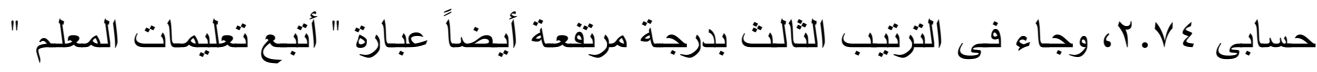

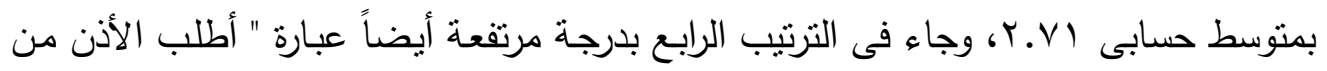

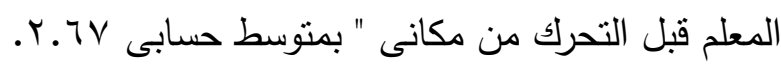




\section{V استجابات المبحوثين على مقياس مهارة الصدق:}

يبين الجدول التالى التكرارات والنسب المئويـة والمتوسطات الحسابية لدرجة استجابات

مفردات عبنة الدراسة على مقياس مهارة الصدق كأحد أبعاد المهارات الاجتماعية.

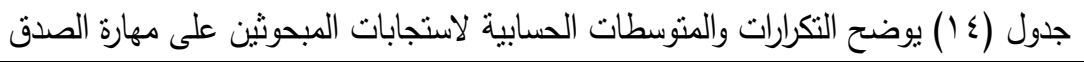

\begin{tabular}{|c|c|c|c|c|c|c|c|c|c|c|}
\hline \multirow{2}{*}{ ?. } & \multirow{2}{*}{ 雮! } & \multirow{2}{*}{$\begin{array}{l}\bar{x} \\
\overline{1} \\
\overline{9}\end{array}$} & \multirow{2}{*}{$\begin{array}{ll}\overline{3} & \overline{7} \\
\frac{3}{3} & 3\end{array}$} & \multicolumn{2}{|c|}{$y$} & \multicolumn{2}{|c|}{ أحيانا } & \multicolumn{2}{|c|}{ نعم } & \multirow{2}{*}{ العبارة } \\
\hline & & & & $\%$ & ك & $\%$ & ك5 & $\%$ & ك & \\
\hline مرتنع & $r$ & .07 & T.OE & $T . r v$ & Ir & ra.rr & $1 \leqslant$. & OV.r. & $r \cdot \varepsilon$ & كان أنحدث بصدق فئما حتى ولو \\
\hline مرتنع & 1 & .09 & T.T4 & 7.11 & rr & r..ro & VI & VT.\&V & rol & لا أكنب على أصدق أو على \\
\hline مرتفع & $r$ &..$v$. & r.07 & $1 \% . r 4$ & $\varepsilon \varepsilon$ & 19.1. & $\pi$ & 71.0\{ & $r \leqslant \varepsilon$ & لا أقدول أسرار \\
\hline مرتفع & - &.$\pi r$ & r. .09 & & & & & & & التصميم ككل \\
\hline
\end{tabular}

يتضح من الجدول السابق أن مهارة الصدق حصلت على درجة (مرتفعة)، حيث حصلت

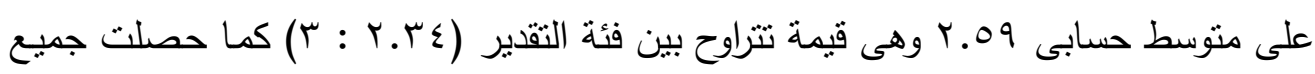
عبارات هذا المجال على درجة تقدير مرتفع، وكانت أعلى هذه العبارات ترتيبا هى" لا أكذب

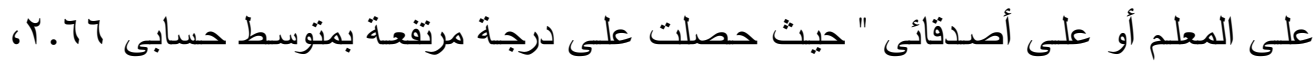

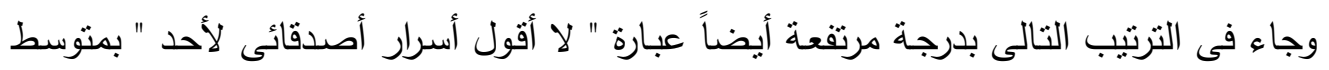

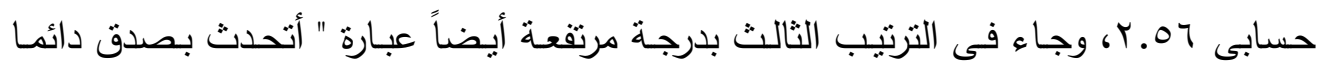

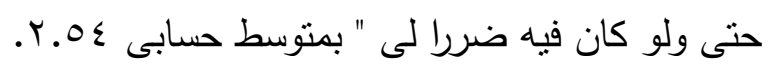

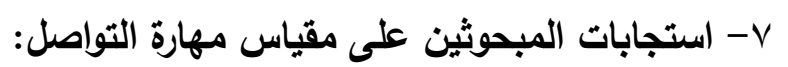

يبين الجدول التالى التكرارات والنسب المئويـة والمتوسطات الحسابية لدرجـة استجابات مفردات عينة الدراسة على مقياس مهارة التواصل كأحد أبعاد المهارات الاجتماعية. 
جدول (0) يوضح النكرارات والمنوسطات الحسابية لاستجابات المبحوثين على مهارة التواصل

\begin{tabular}{|c|c|c|c|c|c|c|c|c|c|c|}
\hline \multirow[b]{2}{*}{ ?.? } & \multirow[b]{2}{*}{ ?! } & \multirow[b]{2}{*}{$\frac{7}{7}=$} & \multirow[b]{2}{*}{$\begin{array}{l}\overline{3} \\
\frac{3}{3} \\
7\end{array}$} & \multicolumn{2}{|l|}{$y$} & \multicolumn{2}{|l|}{ أحيانا } & \multicolumn{2}{|l|}{ نعم } & \multirow[b]{2}{*}{ العبارة } \\
\hline & & & & $\%$ & & $\%$ & & $\%$ & & \\
\hline رتفع & & . & $\begin{array}{r}r \\
. r \Lambda\end{array}$ & $\begin{array}{ll}1 & \\
\varepsilon .71\end{array}$ & $r$ & $\begin{array}{ll}r & \\
r .10\end{array}$ & 11 & $\begin{array}{l}\text { O T.YO } \\
\text { T. }\end{array}$ & 17 & أعبر عن مشاعري الحصة \\
\hline مرتقع & $\varepsilon$ & .00 & Y. $\leqslant \Lambda$ & Y.AI & 1. & $\varepsilon 7 . \cdot v$ & $17 \varepsilon$ & 01.11 & INT & أصنى جيدا لشرح \\
\hline مرتفع & 1 & .01 & Y.VY & r.AI & 1. & YY. $\leqslant V$ & $\Lambda$. & $V \varepsilon . V Y$ & YTT & أبدأ بالحوار مع الآخرين \\
\hline مرتفع & $r$ & $.0 r$ & Y.07 & $1.1 \mathrm{r}$ & $\varepsilon$ & $\varepsilon r . \mid T$ & 10. & $07 . V \leqslant$ & $r \cdot r$ & أصدقائى باستمرار \\
\hline مرتفع & $r$ & .7 & Y.VT & V.AV & $r \wedge$ & $11 . \wedge$ & $\varepsilon r$ & $\Lambda . r \leq$ & rAT & شرح أسئلة أثناء \\
\hline مرتقع & - &. .01 & r.ov & צه & & & & & & التصميم ككل \\
\hline
\end{tabular}

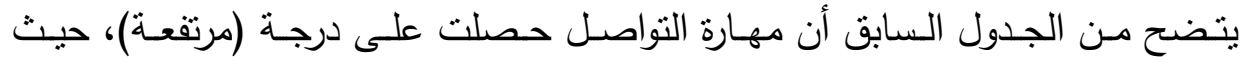

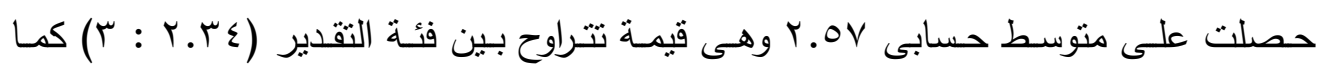

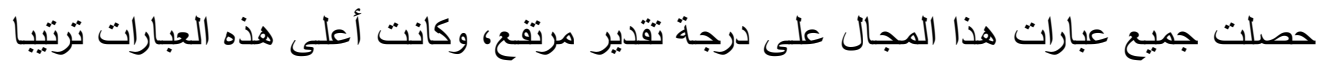

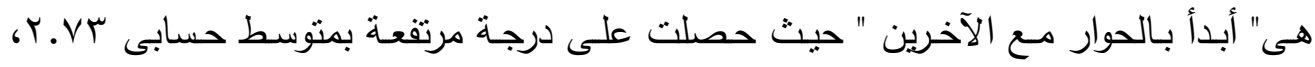

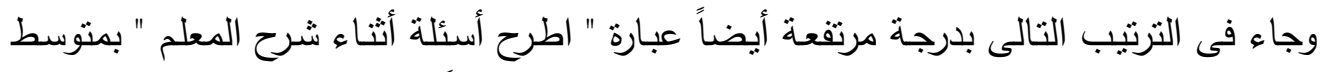

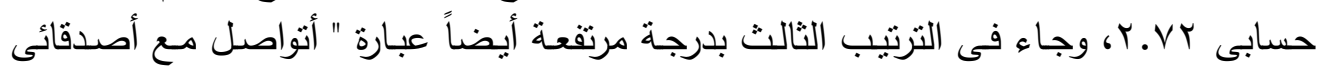

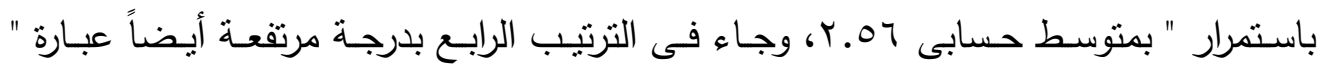

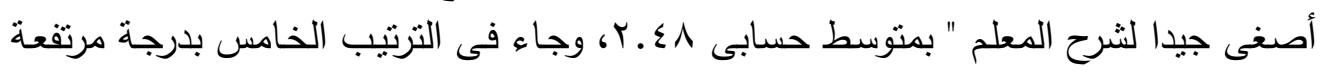

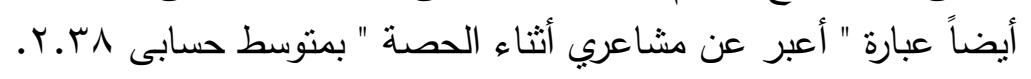

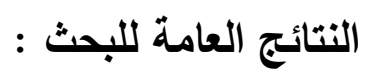

توصلت نتائج البحث إلى أن أغانى الأطفال المقدمة بالقنوات التليفزيونية المتخصصة

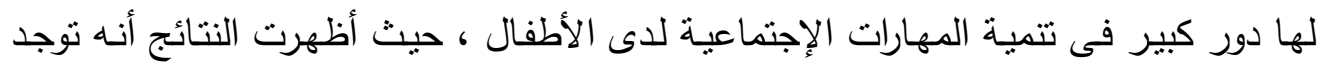

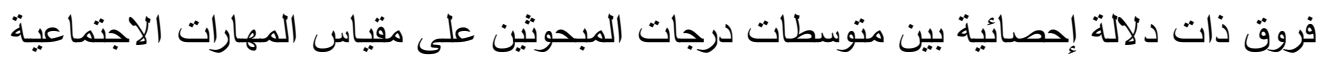

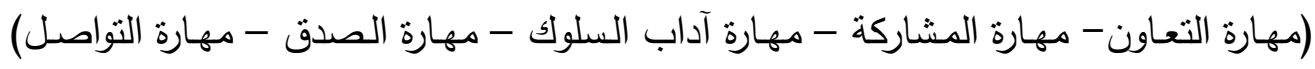

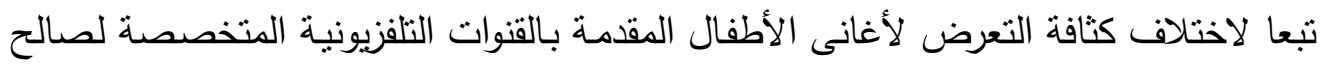

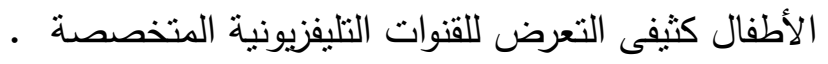




\section{توصيات البحث ومقترحاته :}

فى ضوء النتائج التى أسفرت عنها هذه الاراسة تقدم الباحثة عددا من التوصيات التى تامل أن تفيد المسئولين والمهتمين ،وتتمثل هذه التوصيات فيما يلى :

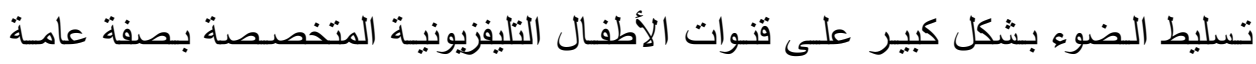

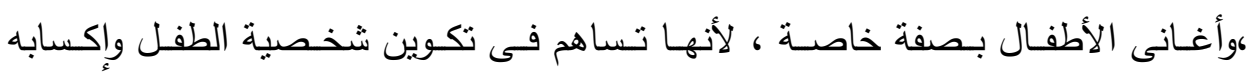

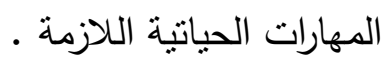
البدء فى تتظيم مؤتمرات وندوات للأطفال لغرس ونشر مفـاهيم المهارات الإجتماعيـة

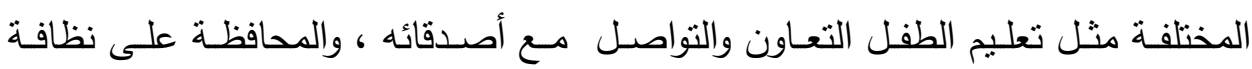
المكان ، وقول الحقيقة دائما ، والالتزام بالنظام .

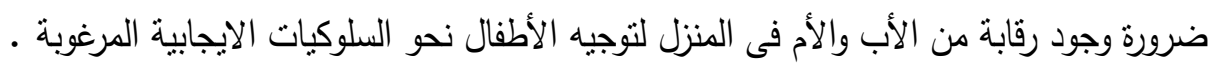

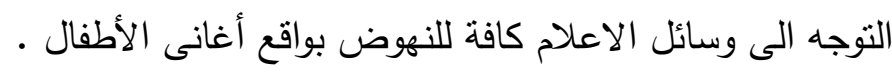

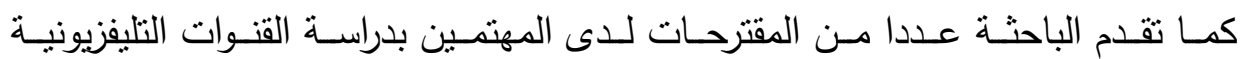
المتخصصة بصفة عامة وأغانى الأطفال بصفة خاصة والتى بمكن أن تكون لها ثمار عظيهة إذا تم دراستها بشكل جيد :

استخدام وسائل التكنولوجيا من تطبيقات حديثة على الهاتف مع الأطفال لتتمية مهاراته

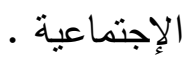
قيام بحوث تحليلية حول محتوى الأغانى الموجهة إلى الأطفال للوقوف على الثغرات التى

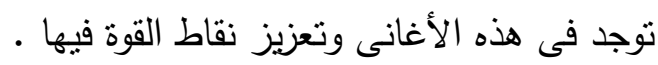




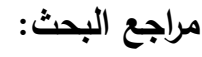

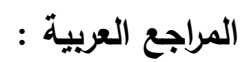

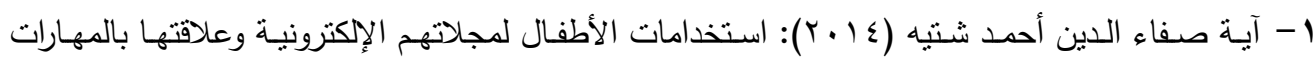

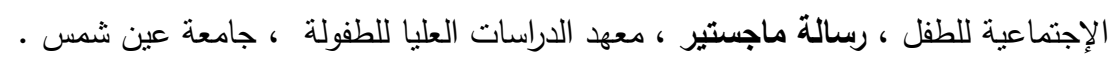

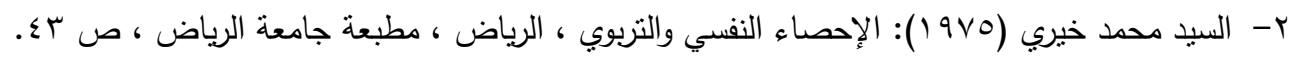

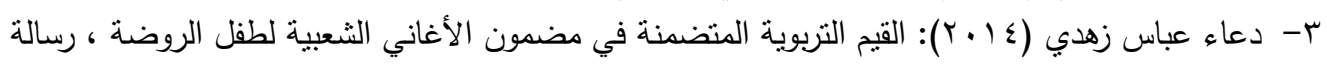
دكتوراة، كلية التربية ، جامعة طنطاء

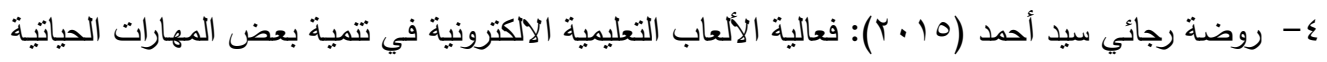

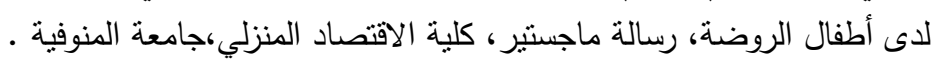

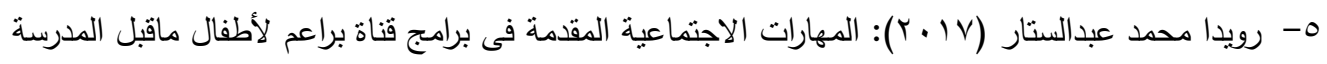

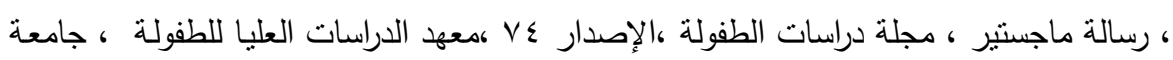

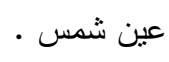

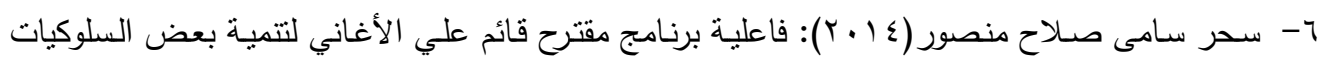

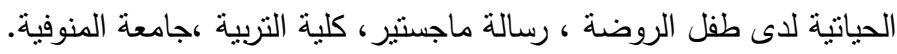

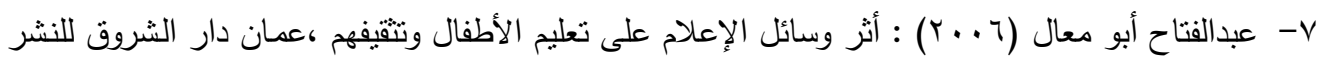

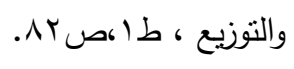

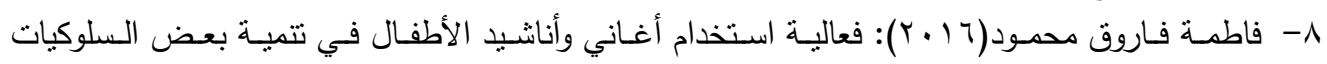

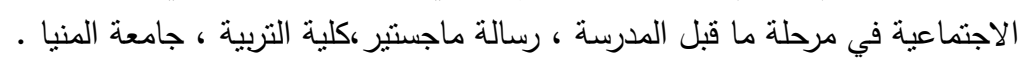

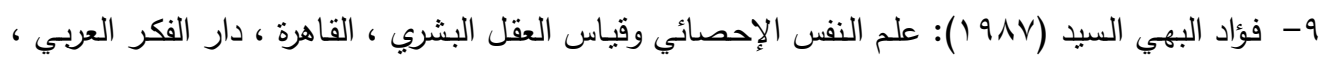
ص.07.

.

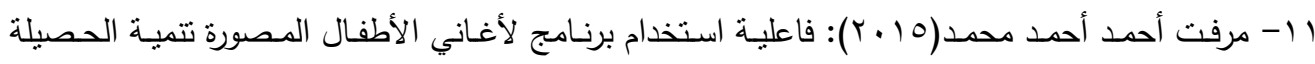

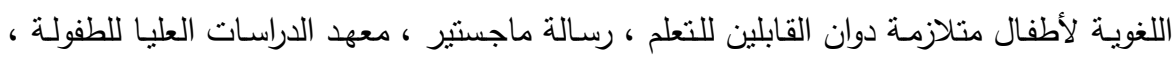

$$
\text { جامعة عين شمس . }
$$

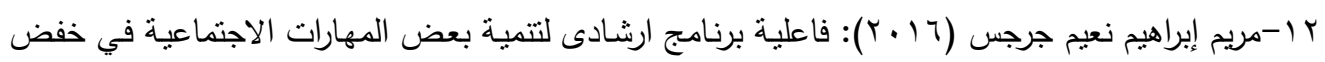

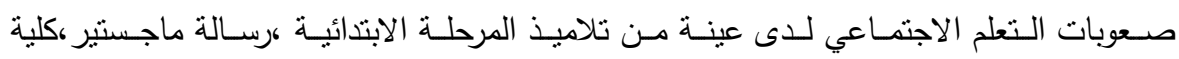

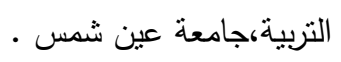

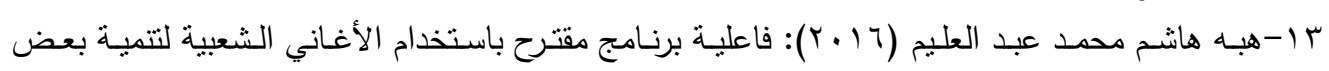

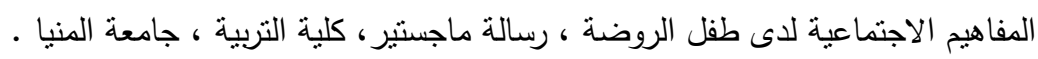

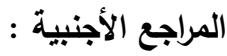

I ¿- Hunter, Linda Sue(1994) "The Influence Of the Medium on Children's Comprehension of Narrative $\mathbf{P h}$ :D . University of Illinois Atllrbanac Champaign, 1991 In DAJ, vol. or, no. 11 , May 199 .

10-Goldstein,R,Miklowitz,Mullen,K.(Y..7) :"Social skills knowledge and among adolescents with bipolar disorder", Bipolar Disorder,VOL 